\title{
RC Structures Cyclic Behavior Simulation with a Model integrating Plasticity, Damage and Bond-Slip
}

\author{
Short title: RC Structures Simulation integrating Plasticity, Damage and Bond-Slip
}

\author{
B. Alfarah ${ }^{1}$, J. Murcia-Delso ${ }^{2}$, F. López-Almansa ${ }^{3}$, S. Oller ${ }^{4}$ \\ ${ }^{l}$ PhD Candidate, Technical University of Catalonia, Civil and Environmental Engineering Department, Campus Nord UPC, \\ 08034 Barcelona, Spain \\ ${ }^{2}$ Assistant Professor, Department of Civil, Architectural and Environmental Engineering, 301E E Dean Keeton St C1700, \\ Austin, TX 78712 \\ ${ }^{3}$ Professor, Technical University of Catalonia, Architecture Technology Department, Avda. Diagonal 649, 08028 Barcelona, \\ Spain \\ ${ }^{4}$ Professor, Technical University of Catalonia, Civil and Environmental Engineering Department, Campus Nord UPC, 08034 \\ Barcelona, Spain
}

Correspondence to: Francisco López-Almansa; Departament d'Estructures; ETSAB (UPC); Avda. Diagonal 649; 08028 Barcelona (Spain); Phone +34934016316, FAX +34934016096; E-mail:

francesc.lopez-almansa@upc.edu

Summary: The behavior of reinforced concrete structures under severe demands, as strong ground motions, is highly complex; this is mainly due to the complexity of concrete behavior and to the strong interaction between concrete and steel, with several coupled failure modes. On the other hand, given the increasing awareness and concern on the worldwide seismic risk, new developments have arisen in earthquake engineering; nonetheless, some developments are mainly based on simple analytical tools that are widely used, given their moderate computational cost. This research aims to provide a solid basis for validation and calibration of such developments using computationally-efficient continuum mechanics-based tools. Within this context, this paper presents a model for 3-D simulation of cyclic behavior of RC structures. The model integrates a bond-slip model developed by one of the authors and the damage variables evolution methodology for Concrete Plastic Damage Model (CDPM) developed by some authors. In the integrated model, a new technique is derived for efficient 3-D analysis of bond-slip of two or more crossing reinforcing bars in beam-column joints, slabs, footings, pile caps and other similar members. The analysis is performed by implementing the bond-slip model in a user element subroutine of Abaqus and the damage variables evolution methodology in the original CDPM in the package. Two laboratory experiments consisting of a column and a frame subjected to cyclic displacements up to failure are simulated with the proposed formulation.

Keywords: Concrete Plastic Damage Model, Bond-Slip Model, Numerical Simulation, Concrete Structures, Cyclic Behavior.

\section{Introduction}

Under severe seismic excitation, structural behavior of buildings and other constructions is highly complex. It involves, among other issues, soil-structure interaction, large strains and displacements, damage, plasticity, and near-collapse behavior. Moreover, in reinforced concrete structures, there are several coupled degradation and failure modes: cracking, crushing and spalling of concrete, yielding, bond-slip and pull-out of tensioned reinforcement, and yielding, buckling and rupture of compressed reinforcement. Therefore, in earthquake engineering, advanced numerical simulations based on continuum mechanics are strongly necessary; conversely, oversimplified models are commonly used, as a result of their moderate computational cost. Furthermore, another circumstance makes the situation more alarming: given the increasing awareness and concern on the huge worldwide seismic risk, earthquake engineering has recently experienced substantial advances; new design and analysis strategies have been proposed (CBD, PBD, pushover analysis, IDA, among others), leading to relevant developments. These developments rely on extensive testing and numerical simulation; nonetheless, as discussed before, an important number of numerical analyses are mainly conducted by using simplified models. Therefore, there is a strong need of verifying the reliability of the new developments by comparison with analyses performed using more 
advanced simulation tools. Being aware of this circumstance, the authors have started a long-term research activity aiming to clarify this issue and to provide accurate and reliable models that are based on continuum mechanics. In previous works [López-Almansa et al. 2014; Bashar et al. 2017], the authors have proposed a new methodology for calculating the damage variables of Concrete Damage Plastic Models (CDPM); this methodology had been implemented in Abaqus, thus generating a model for simulation of the structural behavior of RC frames. It has proven satisfactory for describing monotonic experiments on RC frames; cyclic performance is only verified on plain concrete. The model does not contemplate sliding between reinforcement bars and the surrounding concrete (perfect bond); therefore, it might be not completely suitable for earthquake engineering, since sliding can be highly relevant in cyclic behavior. This paper extends the capabilities of this model by incorporating a formulation for describing reinforcement bond-slip developed by one of the authors [Murcia-Delso 2013; Murcia-Delso et al. 2013; Murcia-Delso, Shing 2015a, 2015b]; this formulation had been verified with monotonic and cyclic pull-out tests, as well as large-scale tests of bridge pier-shaft systems. The resulting integrated model is aimed to reproduce accurately and reliably, although with a rather moderate computational cost, the cyclic behavior of 2-D RC frames under severe degradation conditions.

Given the accuracy and reliability of the proposed model, it can be utilized for calibration of more simplified algorithms. As well, its numerical efficiency make it suitable for research, typically nonlinear dynamic analysis of concrete buildings undergoing strong ground motion excitation. A study for reproducing with the proposed model the hysteretic behavior of connections between RC columns and building waffle slabs is currently in progress.

\section{State of the art}

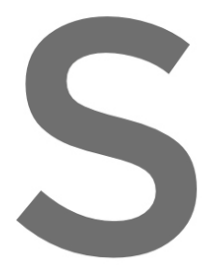

\subsection{Concrete Plastic Damage Models}

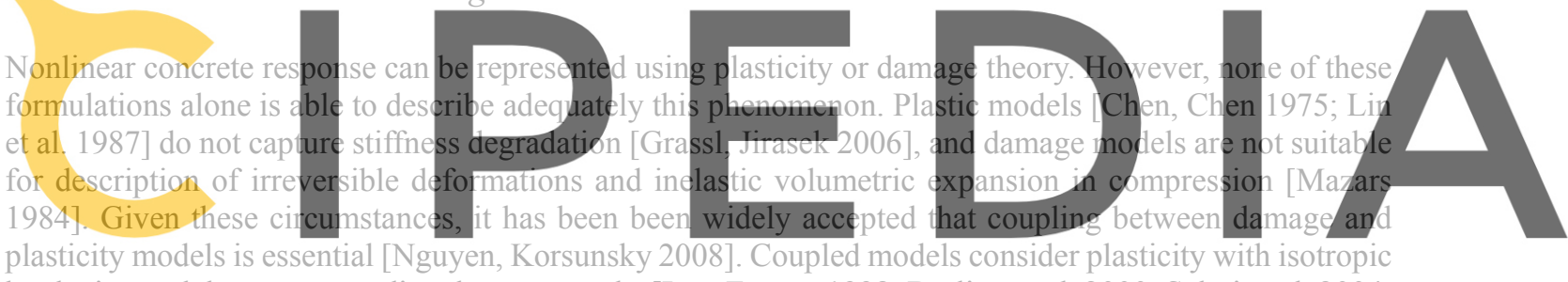

plasticity models is essential [Nguyen, Korsunsky 2008]. Coupled models consider plasticity with isotropic hardening and damage; regarding damage, works [Lee, Fenves 1998; Burlion et al. 2000; Salari et al. 2004;

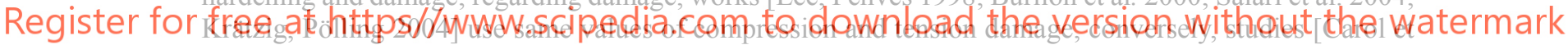

al. 2001; Voyiadjis et al. 2008] consider differences among them. In addition, fracture propagation can be represented by embedded crack models, where standard FEM interpolations are enriched with strain or displacement discontinuities [Belytschko et al. 1988; Simo, Oliver 1994; Jirásek, Zimmermann 2001]. These models can be used for high strain localization problems (fracture).

Coupled damage and plasticity models differ mainly in the coupling method and the damage evolution law. In the implicit methods [Luccioni et al. 1996; Nguyen, Houlsby 2004; Salari et al. 2004], coupling and damage evolution law are embedded in yield and damage criteria. Other researchers describe coupling using a single function. In this context, [Lee, Fenves 1998; Lemaitre 1992] use a yield function; inside it, damage can be measured either following some criteria (e.g. a threshold based on the equivalent plastic strain [Lemaitre 1992]) or obtained imposing damage variables laws. [Faria et al. 1998] use a damage loading function where damage evolution law shall be imposed.

A major problem in implementation of any Plastic Damage Model is the calculation of the damage variables that govern damage evolution. A number of researchers have proposed methodologies for selecting such variables:

- [Mazars, Pijaudier-Cabot 1989]. The damage variables are obtained from parameters derived from experiments on specimens and beams. It is concluded that damage formulations describe adequately the behavior of reinforced concrete, and agreement with experimental results is achieved.

- [Birtel, Mark 2006]. Tension and compression damage variables are calculated by assuming constant ratios between compressive plastic and crushing strains, and between tensile plastic and cracking strains, respectively. These fixed ratios are calibrated with an experimental curve. 
- [Häussler-Combe, Hartig 2008]. A damage evolution function is used. It depends on four material parameters to be calibrated with experimental results.

- [Yu et al. 2010]. This work focuses on confined concrete. A linear expression of damage variable vs. stress is proposed for the compressive descending branch (compressive damage). As well, modified linear expressions in terms of confining pressure and stress invariants are suggested.

- [Al-Rub, Kim 2010]. This work focuses on plain concrete. Tensor damage variables that are separated into compressive and tensile parts are proposed. The evolution of damage variables is derived by identification with loading-unloading uniaxial test results. Two different damage evolution laws for tension and compression are proposed.

- [Zheng et al. 2012]. The function developed by [Mazars, Pijaudier-Cabot 1989] is used to analyze the damage evolution. Damage constants also have to be calibrated from experiments.

- [López-Almansa et al. 2014]. Damage variables are determined by an iterative empirical procedure aiming to fit experimental results.

After these investigations, some of the authors proposed [Alfarah et al. 2017] a new approach for obtaining damage variables. This methodology is based on the formulation by Lubliner and Lee/Fenves [Lubliner et al. 1989; Lee, Fenves 1998], which is the base for the Abaqus plastic damage model for concrete. After integration of concrete fracture and crushing energy, the proposed approach obtains closed-form expressions of the damage variables in terms of the corresponding strains. No calibration with experimental results is required and a strategy aiming to avoid mesh-dependency is incorporated.

This approach can consider any concrete constitutive law, either empirical (e.g. like formulations commonly recommended by design codes) or directly based on particular experiments. A particular algorithm using laws based on European recommendations was derived and implemented in the software package Abaqus [Abaqus 2013]. This algorithm was used for describing cyclic experiments on plain

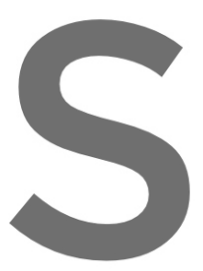
concrete and monotonic tests on full-scale RC frames. The objective of this research is to validate this model under cyclic loading and enhance its perfornanee for simulation of RC frames by incorporating bond-slip model.

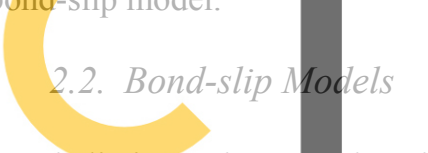

Bond-slip is a rather complex phenemenon since in
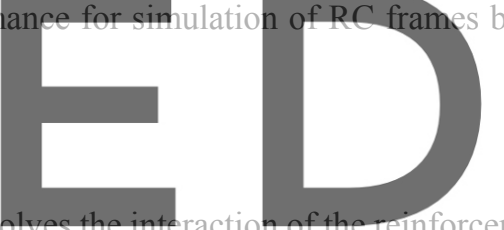

surrounding concrete under severe loading conditions, which severely deform the reinforcing bars and

Rib scale. The detailed geometry of the interface, including bar ribs, is modelled, and concrete and steel are discretized with continuum elements [Maekawa et al. 2003, Daoud et al. 2012]. These models can provide very high accuracy, although with a high computational cost.

Bar scale. Ribs are not directly included in the simulation; the contact surface is idealized as smooth. Concrete and steel can be discretized with different types of elements (e.g. solid for concrete and truss or beam for steel). The interaction forces (cohesion, friction and bearing) are represented by tangential (bond) and normal stress; particular attention is usually paid to the tangential component. Bond-slip is represented through relation between bond stress and bar slip implemented in zero-thickness interface element. [Lowes et al. 2004] developed a four-node zero-thickness bond-slip element to be used for two-dimensional modelling; other studies using this model have been reported. Broadly speaking, bar scale models have good balance between computational cost and ability to reproduce accurately bond behavior.

Structural Element scale. The bond-slip effects are either incorporated in the formulation of the element or taken into consideration through zero-length springs. [Monti, Spacone 2000] introduced the beam-column model with bond-slip proposed by [Monti et al. 1997] into the force-based fiber-section element developed by [Spacone et al. 1996]. [Zhao, Sritharan 2007] proposed a law to relate bar stress and slip at end of anchorage in footing-column or beam-column connections; this law has been calibrated with experimental results and used as a constitutive relation for steel fibers in a zero-length fiber-section element to simulate end rotation of RC columns. These models have low computational cost and, therefore, are suitable for simulation of full-scale structures; conversely, they do not study explicitly the bond behavior, merely reflect the additional flexibility provided by bond-slip. 
Rib scale models are too computationally expensive for the practical simulation of full-scale actual structures, and element scale models can be an attractive option for large-scale simulation but cannot capture strength reduction due to bond degradation (because of slip, concrete spalling or steel yielding) and cannot be implemented in continuum elements. Bar scale models are the most appropriate for implementation in continuum elements under seismic excitation, as they represent efficiently interaction between two materials and predict different deterioration modes. A number of models of this type have been proposed:

- [Gan 2000]. A double-node zero-thickness contact element is used to connect steel bar elements with the surrounding concrete. The monotonic and cyclic behavior of this element is governed by a bond-slip law originally proposed by [Eligehausen et al. 1983] and later modified by [Gan 2000] according to experimental observations. This contact element was implemented in Finite Element Code TRIX99 and used to perform 2-D cyclic analysis for shear walls.

- [Ožbolt et al. 2002]. These researchers proposed a monotonic bond-slip law based on experimental results [Eligehausen et al. 1983; Malvar 1992]. This law was implemented in the finite element code MASA using a zero-width element. Concrete and steel are discretized with solid and truss elements, respectively. This model was been verified with pull-out tests and simply-supported RC beams.

- [Lowes et al. 2004]. A four-node zero-thickness bond-slip element is used for two-dimensional monotonic and cyclic modelling. The model is characterized by a normalized bond stress-slip law and a relation between the maximum bond strength and stress-strain state of concrete and steel.

- [Rabczuk et al. 2005]. A 2-D two-double-node interface element, bond behavior is described in terms of radial stress-strain relation. This element was implemented in FE package Abaqus using user subroutine; it was used in the simulation of a prestressed RC beam subjected to static load.

[Murcia-Delso, Shing 2015a]. These researchers developed a general 3-D bond-slip model
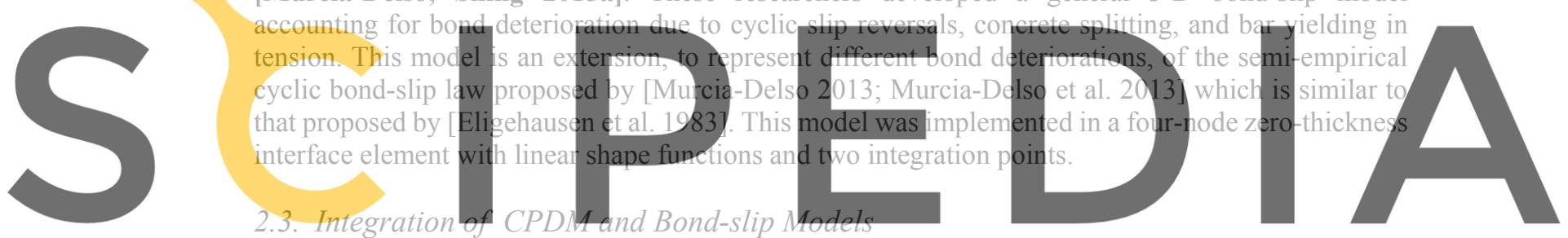

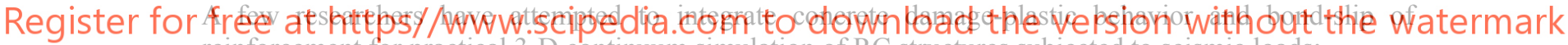
reinforcement for practical 3-D continuum simulation of RC structures subjected to seismic loads:

- [Car et al. 2002]. These researchers proposed a constitutive model based on assuming that stress transfer from concrete to steel depends on concrete damage and steel strength. Slip is represented by an irrecoverable inelastic steel strain.

- [Deaton 2013]. Proposed a general model to study the 3-D cyclic behavior of non-seismic RC beam-column joints. Concrete behavior was represented by a damage model originally developed by [Vecchio, Collins 1986] and implemented in the FE analysis program DIANA. Bond-slip was described with an interface model "line-to-solid" that follows a built-in stress-slip hysteretic law. Verifications with experimental results showed the inability of the bond model to represent the actual hysteretic behavior; concrete model showed good capacity to represent the capacity envelope but not the dissipated energy.

- [Ali et al. 2013]. Studied the cyclic behavior of composed concrete-steel shear walls. The original CDPM that is implemented in Abaqus was used to simulate concrete behavior; bond-slip is described with contact conditions. Comparison with experimental results, pointed out the lack of capturing the pinching effect (due to bond degradation and cracks opening-closing) and the strength degradation.

- [Murcia-Delso 2013]. The 3-D bond-slip model was used together with the original CDPM that is implemented in Abaqus. It is calibrated with pull-out tests and utilized to simulate 3-D cyclic behavior of RC columns supported on enlarged pile shaft foundations; satisfactory agreement was obtained. Discrete cracks were introduced at column base to simulate opening and closing of wide flexural cracks at this location and circumvent limitations of the CDPM in Abaqus to handle the large stiffness degradation required to accurately represent cyclic response of cracks. 


\section{Calculation of Damage Variables for Concrete Plastic Damage Model}

As discussed in Section 2, calculating the evolution of damage variables in Concrete Plastic Damage Models is a crucial issue. This section summarizes the algorithm proposed by [Alfarah et al. 2017] for obtaining the damage variables and its implementation in Concrete Damage Plastic Models.

In the considered CPDM [Lubliner et al. 1989; Lee, Fenves 1998], stiffness degradation in the uniaxial cyclic behavior is described as:

$$
E=(1-d) E_{0}
$$

In equation (1), $E_{0}$ is the initial (undamaged) elastic stiffness, $E$ is the reduced tangent stiffness and $d$ is a scalar degradation variable, which is a function of stress state and compression and tension damage variables $d_{\mathrm{c}}$ and $d_{\mathrm{t}}$, respectively:

$$
1-d=\left(1-s_{\mathrm{t}} d_{\mathrm{c}}\right)\left(1-s_{\mathrm{c}} d_{\mathrm{t}}\right)
$$

In equation (2), $s_{\mathrm{c}}$ and $s_{\mathrm{t}}$ are dimensionless coefficients accounting for stress state and stiffness recovery effects, being given by

$$
\begin{gathered}
S_{\mathrm{c}}=1-h_{\mathrm{c}}\left(1-r^{*}\left(\sigma_{11}\right)\right) \\
S_{\mathrm{t}}=1-h_{\mathrm{t}} r^{*}\left(\sigma_{11}\right)
\end{gathered}
$$

In equations (3) and (4), $\sigma_{11}$ is the first principal uniaxial stress (positive for tension), $r^{*}$ is a stress state parameter being $r^{*}\left(\sigma_{11}\right)=1$ for tension and $r^{*}\left(\sigma_{11}\right)=0$ for compression, and $h_{\mathrm{c}}$ and $h_{\mathrm{t}}$ are weighting factors ranging between 0 and reversal; $h_{\mathrm{t}}$ represents i.e. crushed concrete concrete bodies $(90 \%$ show that $S_{\mathrm{C}}$ and $s_{\mathrm{t}}$ range between 0 and 1 . Further explanation on the effect of $s_{\mathrm{c}}$ and $s_{\mathrm{t}}$ and the constitutive equations of the 3-D model can be found in [Alfarah et al. 2017; Alfarah 2017].

The methodology to obtain the damage evolution proposed by [Alfarah et al. 2017] is based on assuming that compressive and tensile damage variables are the portions of normalized energy dissipated by damage:

$$
d_{\mathrm{c}}=\frac{1}{g_{\mathrm{c}}} \int_{0}^{\varepsilon_{\mathrm{c}}^{\mathrm{ch}}} \sigma_{\mathrm{c}} \mathrm{d} \varepsilon_{\mathrm{c}}^{\mathrm{ch}} \quad d_{\mathrm{t}}=\frac{1}{g_{\mathrm{t}}} \int_{0}^{\varepsilon_{\mathrm{t}}^{\mathrm{ck}}} \sigma_{\mathrm{t}} \mathrm{d} \varepsilon_{\mathrm{t}}^{\mathrm{ck}}
$$

In equation (5), $\varepsilon_{\mathrm{c}}^{\mathrm{ch}}$ and $\varepsilon_{\mathrm{t}}^{\mathrm{ck}}$ are crushing and cracking strain defined as the inelastic compressive and tensile strain, respectively [Alfarah et al. 2017]. Normalization coefficients $g_{\mathrm{c}}$ and $g_{\mathrm{t}}$ represent the energies per unit volume dissipated by damage along the entire deterioration process:

$$
g_{\mathrm{c}}=\int_{0}^{\infty} \sigma_{\mathrm{c}} \mathrm{d} \varepsilon_{\mathrm{c}}^{\mathrm{ch}} \quad g_{\mathrm{t}}=\int_{0}^{\infty} \sigma_{\mathrm{t}} \mathrm{d} \varepsilon_{\mathrm{t}}^{\mathrm{ck}}
$$

Equations (5) and (6) show that $d_{\mathrm{c}}$ and $d_{\mathrm{t}}$ range between 0 (no damage) and 1 (destruction). Figure 1 describes the meaning of $g_{\mathrm{c}}$ and $g_{\mathrm{t}}$. 


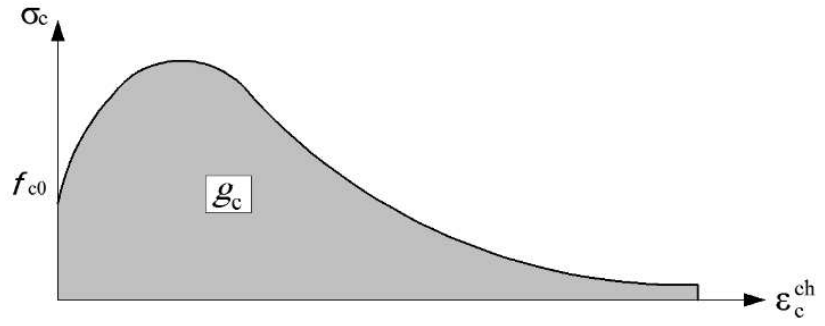

(a) Compression $\left(g_{c}\right)$

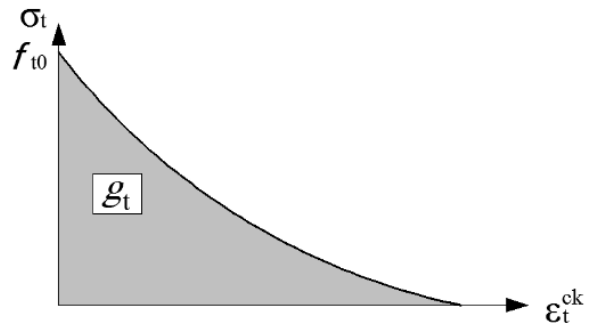

(b) Tension $\left(g_{\mathrm{t}}\right)$

Figure 1. Portions of energy dissipated by damage [Alfarah et al. 2017]

Noticeably, the energies per unit area and per unit volume are related by $g_{\mathrm{c}}=G_{\mathrm{ch}} / l_{\mathrm{eq}}$ and $g_{\mathrm{t}}=$ $G_{\mathrm{F}} / l_{\mathrm{eq}} ; G_{\mathrm{ch}}$ and $G_{\mathrm{F}}$ are material parameters defined as crushing and fracture energies by unit area and $l_{\text {eq }}$ is the characteristic length of the finite element, which depends on the mesh size, the type of element and the crack direction [Oliver 1989; Krätzig, Pölling 2004]. In this paper, an idealized behavior of single band of cracks is assumed; therefore, the characteristic length is taken as the average of the brick (solid) element size.

Compressive and tensile damage evolution laws are defined according to [Alfarah et al. 2017] in equations (7) and (8).
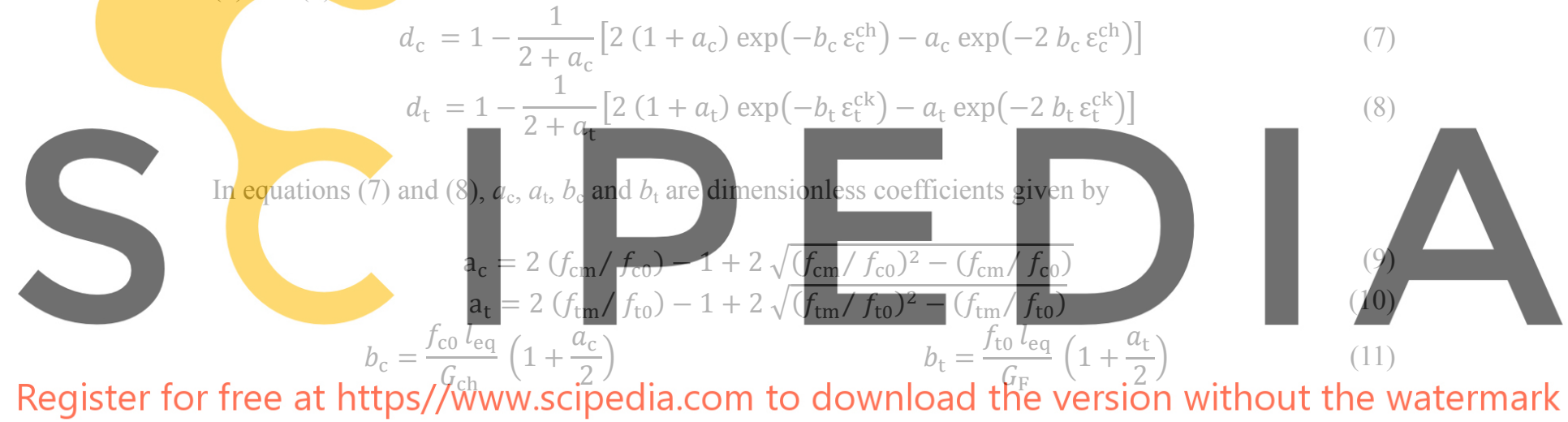

In equations (9), (10) and (11), $f_{\mathrm{c} 0}$ and $f_{\mathrm{t} 0}$ are the compressive and tensile stresses that correspond to zero crushing $\left(\varepsilon_{\mathrm{c}}^{c h}=0\right)$, and to onset of cracking $\left(\varepsilon_{\mathrm{t}}^{\mathrm{ck}}=0\right)$, respectively; $f_{\mathrm{cm}}$ and $f_{\mathrm{m}}$ are the maximum compressive and tensile stress, respectively.

Implementing the damage evolution algorithm in the CPDM requires the concrete compression and tension stress-strain relation to be determined. The concrete uniaxial law described in [Alfarah et al. 2017] is used in this study; then, coefficients $a_{\mathrm{c}}, a_{\mathrm{t}}, b_{\mathrm{c}}$ and $b_{\mathrm{t}}$ are determined:

$$
a_{\mathrm{c}}=7.873 \quad a_{\mathrm{t}}=1 \quad b_{\mathrm{c}}=\frac{1.97\left(f_{\mathrm{ck}}+8\right)}{G_{\mathrm{ch}}} l_{\mathrm{eq}} \quad b_{\mathrm{t}}=\frac{0.453 f_{\mathrm{ck}}^{2 / 3}}{G_{\mathrm{F}}} l_{\mathrm{eq}}
$$

In equation (12), $f_{\mathrm{ck}}$ is the characteristic value of the compressive strength and $G_{\mathrm{F}}$ is calculated in (13) in $(\mathrm{N} / \mathrm{mm})$ according to [CEB-FIP 2010]. $G_{\mathrm{ch}}$ is obtained in equation (13) assuming that the ratio between crushing and fracture energies is proportional to the square of the ratio between compressive and tensile strengths [Oller 1988]:

$$
G_{\mathrm{F}}=0.073 f_{\mathrm{cm}}^{0.18} \quad G_{\mathrm{ch}}=\left(\frac{f_{\mathrm{cm}}}{f_{\mathrm{tm}}}\right)^{2} G_{\mathrm{F}}
$$

Stresses in equation (13) are expressed in MPa. The abovementioned concrete uniaxial law provides the behavior of the CPDM under uniaxial loading in any direction. Extending the behavior to multiaxial stress conditions is controlled by the CPDM parameters defining the shape of the yield surface and the plastic 
potential [Lubliner et al. 1989; Lee and Fenves 1998]. The selection of these parameters is described in [Alfarah 2017; Alfarah et al. 2017]. Regarding the confinement effect, is not represented by different concrete constitutive laws, but by the direct consideration of the transverse compression exerted by the stirrups; noticeably, such transverse reinforcement bars are explicitly modelled.

After parameters $a_{\mathrm{c}}, a_{\mathrm{t}}, b_{\mathrm{c}}$ and $b_{\mathrm{t}}$, damage variables $d_{\mathrm{c}}$ and $d_{\mathrm{t}}$ are determined by equations (7) and (8) in terms of crushing and cracking strain, respectively.

The major output of the algorithm are curves of compressive / tensile stress and damage variables vs. crushing / cracking strain, respectively. These plots constitute the input of the implementation in any model describing the global structural behavior. This algorithm is suited for software package Abaqus [Abaqus 2013].

\section{Bond-slip Model}

The 3-D interface model proposed by [Murcia-Delso, Shing 2015a] is used to represent the bond relation between the longitudinal reinforcement bars and the surrounding concrete. This model is assigned to a 2-D interface element connecting steel and concrete representing a fraction of the perimeter of the bar. Their interaction is represented in the longitudinal direction by the relation between an equivalent bond stress and the bar slip. The stress-slip constitutive law uses the phenomenological law proposed by [Murcia-Delso et al. 2013] which is based on concepts originally developed by [Eligehausen et al. 1983]. This law was extensively verified by pull-out tests on bars embedded in well confined concrete.

Figure 2 displays the three components of interaction stress $\left(\sigma_{1}, \tau_{2}, \tau_{3}\right)$ and relative displacement $\left(S_{1}, S_{2}, S_{3}\right)$ during sliding.
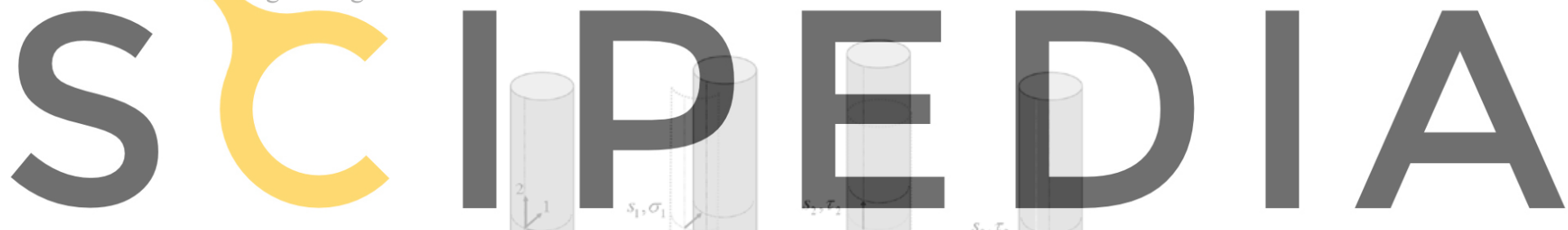

Register for free at https//www.scipedia.com to download the version without the watermark

$\begin{array}{lll}\begin{array}{c}\text { Interface } \\ \text { coordinates }\end{array} & \text { 2. Lormal } & \text { 3. Transverse }\end{array}$

Figure 2. Stress and relative displacement components at bar-concrete interface [Murcia-Delso, Shing

2015a]

The bond resistance $\tau_{2}$ in the model proposed by [Murcia-Delso, Shing 2015a] is decomposed into bearing and friction components:

$$
\tau_{2}=\rho_{\mathrm{n}}\left(\rho_{\mathrm{b}, \mathrm{s}} \rho_{\mathrm{b}, \mathrm{c}} \tau_{\mathrm{b}}+\rho_{\mathrm{f}, \mathrm{s}} \rho_{\mathrm{f}, \mathrm{c}} \tau_{\mathrm{f}}\right)
$$

In equation (14), $\tau_{\mathrm{b}}$ and $\tau_{\mathrm{f}}$ are the full bearing and friction resistance of an elastic bar under monotonic pull-out action. Such resistances are multiplied by reductions factors. $\rho_{\mathrm{b}, \mathrm{s}}$ and $\rho_{\mathrm{f}, \mathrm{s}}$ account for the influence of yielding of bar in tension, $\rho_{\mathrm{b}, \mathrm{c}}$ and $\rho_{\mathrm{f}, \mathrm{c}}$ represent the effect of slip history, and $\rho_{\mathrm{n}}$ takes into consideration splitting cracks and is a function of $S_{1}$.

Figure 3 shows the considered monotonic and cyclic bond stress versus bar slip curves. These curves are defined piecewise using polynomial functions [Murcia-Delso, Shing 2015a] in terms of three parameters: the peak bond strength $\tau_{\max }$, the slip at the pick bond strength $S_{\text {peak }}$ and the clear spacing between the bar ribs $S_{\mathrm{R}}$. 

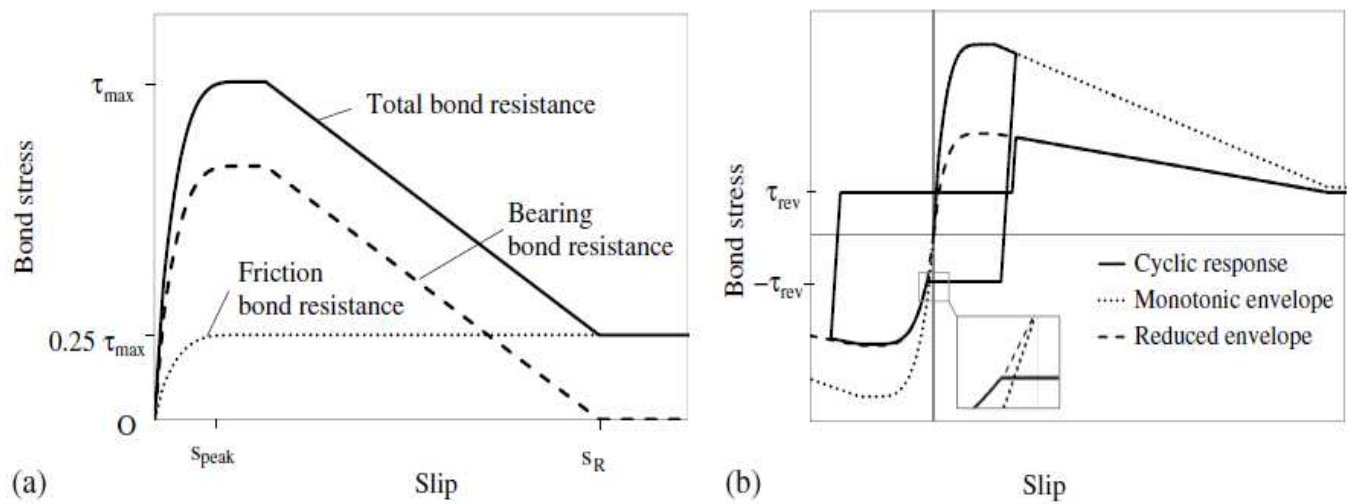

Figure 3. Bond stress-versus-slip law: (a) monotonic response; (b) cyclic response [Murcia-Delso, Shing $2015 \mathrm{a}]$

One of the main features of this model is the consideration of the reduction of bearing and friction resistance because of the diminution of the bar contact area due to yielding in tension [Shima et al. 1987; Liang, Sritharan 2014]. Reduction factors that account for steel yielding in tension are expressed as follows:
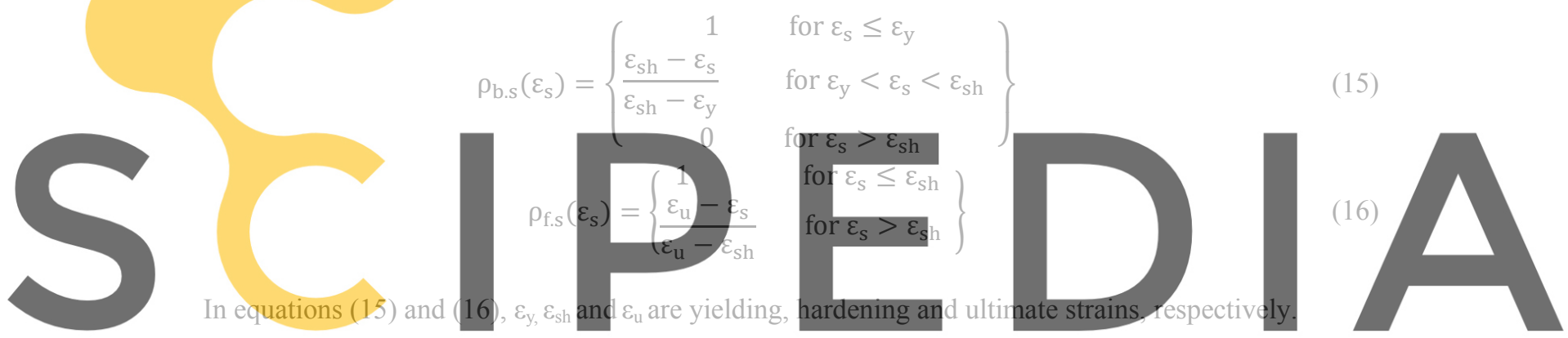

Reduction factors due to the slip history are given by:

Register for free at https//www.scipedia.com to download the version without the watermark $\rho_{\mathrm{b} . \mathrm{c}}=1.2 \mathrm{e}^{-2.7\left(\bar{S}_{\max } / S_{\mathrm{R}}\right)^{0.8}} \leq 1$

$$
\rho_{\text {f.c }}=1-\min \left(\frac{S_{\max }^{+}+S_{\text {max }}^{-}}{S_{\mathrm{R}}}, 1\right)\left(1-\mathrm{e}^{-0.45\left(S_{\text {cum }} / S_{\mathrm{R}}\right)^{0.75}}\right)
$$

In equations (17) and (18), $S_{\max }^{+}$and $S_{\max }^{-}$are the maximum absolute values of slip in positive and negative directions, respectively. $S_{\text {cum }}$ is the cumulated slip after slip exceeds $S_{\text {peak }}$ for the first time. $\bar{S}_{\max }$ is equal to:

$$
\bar{S}_{\text {max }}=0.75 \max \left(S_{\text {max }}^{+}, S_{\text {max }}^{-}\right)+0.25\left(S_{\text {max }}^{+}+S_{\text {max }}^{-}\right)
$$

In this work, the normal displacement $S_{1}$ is assumed to be very small due to the well confined conditions in the region where it is expected that slip occurs. Therefore, the reduction factor that accounts for splitting cracks is equal to $1: \rho_{\mathrm{n}}=1$.

The interface element has two additional components perpendicular to the bar longitudinal axis, one normal and one transverse tangential. The stress-displacement relations in the normal direction represent the splitting stresses introduced by the wedging action of the bar ribs. Assuming that the resultant bond force has a fixed angle of inclination of $60^{\circ}$ as proposed in [Murcia-Delso, Shing 2015a], the normal stress is proportional to the bond stress. For the transverse tangential direction, a penalty stiffness is introduced to restrain the rotation of the bar about its longitudinal axis.

\section{Proposed Implementation Approach}




\subsection{General considerations}

This section describes the two main original contributions of the present study to integrate the damage and bond-slip models. Next subsection presents a new modeling scheme to implement the bond-slip model developed by [Murcia-Delso, Shing 2015] in a FEM analysis, and last subsection describes a new smeared strategy to simulate the reclosing of cracks after tension-compression reversals.

\subsection{Modeling Scheme for Bond-Slip}

The bond-slip model was originally implemented in an interface element in the FEM package Abaqus using the user element subroutine UEL. This interface element can connect truss or beam elements representing reinforcing bars with solid elements representing surrounding concrete, as shown in Figure 4.a. The modeling scheme proposed by [Murcia-Delso, Shing 2015] required the same discretization for steel, interface and concrete elements. This technique is efficient when longitudinal reinforcement consists of parallel bars, but can complicate the mesh when there are crossing bars with non-parallel directions. Figure 4.b describes the basis of the new modeling scheme proposed herein.

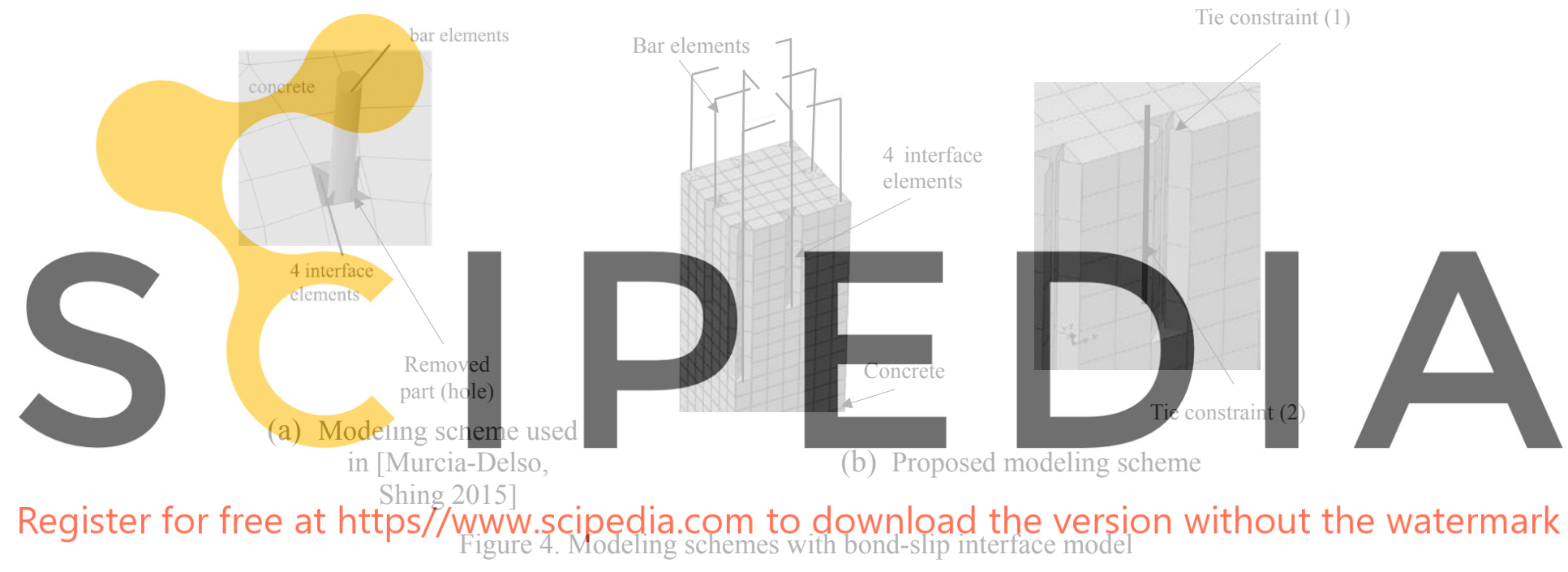

Figure 4.b shows that the proposed technique is based on assigning, for each interface element, a pair of tie-constraint conditions; this being defined as two surfaces having the same degrees of freedom in all the contact points. The softest and stiffest surfaces are slave and master, respectively. The first tie-constraint (1) connects concrete nodes (master surface) with the interface nodes on the concrete side (slave surface). The second constrain (2) ties bar nodes (master surface) and the interface nodes on the bar side (slave surface). Hence, the relative displacement between the concrete and the bar is equal to the relative displacement at the interface element.

Figure 5 illustrates the modeling scheme for two perpendicular crossing bars. Figure 5.b and Figure 5.c show, respectively, that Bar $1(\mathrm{CD})$ and Bar $2(\mathrm{AB})$ are connected to four interface elements each. 


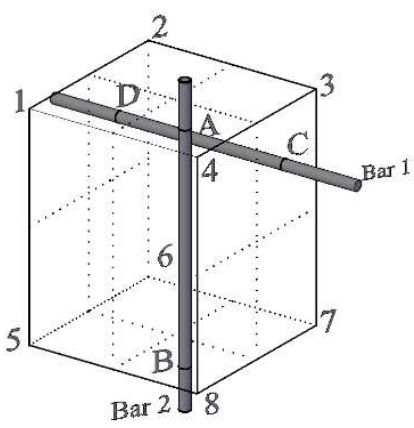

(a) Two bars crossing within a solid element

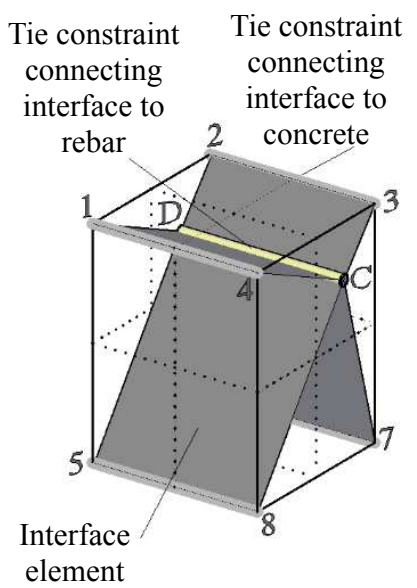

(b) Four inteface elements attached to Bar 1 (CD)

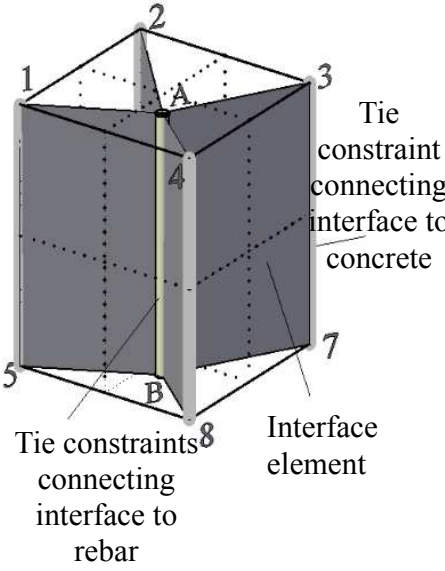

(c) Four inteface elements attached to Bar $2(\mathrm{AB})$

Figure 5. Application of the proposed modeling scheme for two orthogonal longitudinal crossing bars

By using tie constraints, the proposed technique does not require that interface and solid elements have the same diseretization. This strategy aims to overcome meshing problems and convergence difficulties. It is particularly suitable for regions with non-parallel longitudinal reinforcement bars, such as beam-column and slab-column joints, structural walls, foundations, and connections among these elements.
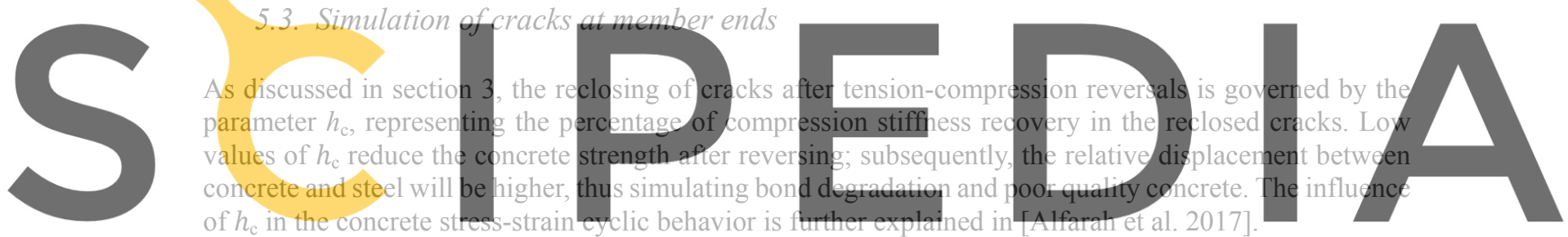

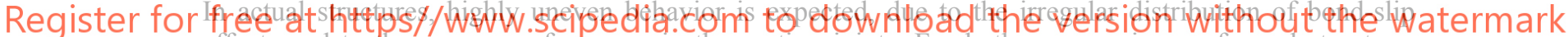 effects and to the poorer performance in the casting joints. For both reasons, in any framed structure, significantly less reclosing of cracks is expected at the member ends and the nearby segments. To enhance} the opening-ciosing simulation of widely opened cracks in the casting joint region, Murcia-Deiso [2013] introduced discrete cracks at the member ends. In the current study, an alternative solution is proposed by using small values of $h_{\mathrm{c}}$ near the member ends; Figure 6 displays a frame modelled with different values of $h_{\mathrm{c}}$. The darkest shadowed zones represent casting discontinuity, and little or no stiffness is expected upon cracks reclosing, therefore $h_{\mathrm{c}}=0.01$. The lightly dark zones correspond to the rest of regions where bond-slip is introduced and $h_{\mathrm{c}}=0.1$ is selected. Finally, in the not-shadowed regions no significant bond-slip effect is expected, and $h_{\mathrm{c}}=0.9$ is chosen. Noticeably, in each of these cases, the results have exhibited little sensitivity to variations of $h_{\mathrm{c}}$ reaching $100 \%$. 


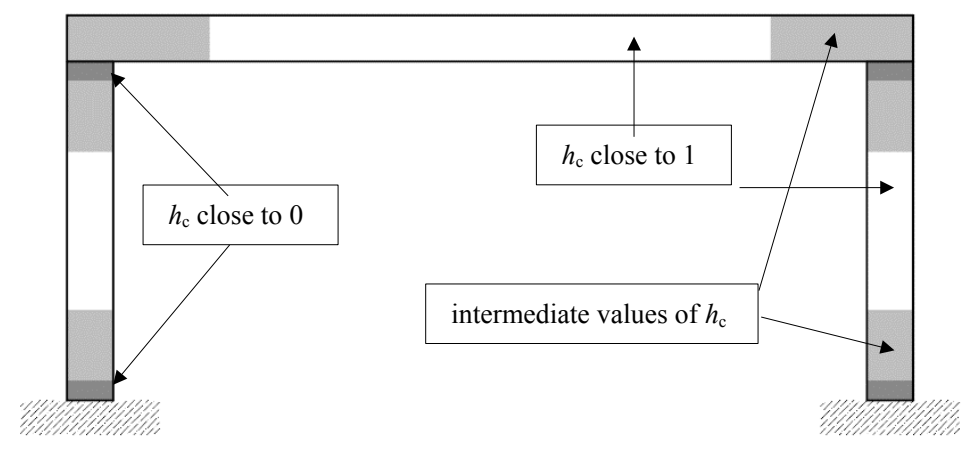

Figure 6. Zones of framed structures with different cracks opening-closing behavior

In practical applications, the darkest shadowed areas in Figure 6 can correspond to the first and last rows of finite elements in the discretization of each column; the lightest shadowed segments can comprise the zones where bond-slip is modelled. Both shadowed regions correspond to the plastic hinge length. In this study, such length is selected according to [Paulay and Priestley 1992]. For cantilever RC columns, it is given by $L_{\mathrm{p}}=0.08 L+0.002 D_{\mathrm{b}} f_{\mathrm{y}}$, where $L$ is the column height, and $D_{\mathrm{b}}$ and $f_{\mathrm{y}}$ are the longitudinal rebar diameter and the steel yield point $(\mathrm{MPa})$, respectively. For RC frames, $L_{\mathrm{p}}$ is half of the section depth.

\section{Simulation of cyclic tests of RC structures}

\subsection{Bridge Column}

Several RC columns have been tested by [Tanaka 1990] to study the effect of lateral confinement on their ductility. Main differences are the type of transverse reinforcement, its anchorage detailing, the axial force, and the mechanical and geometric parameters. Column unit 6 [Tanaka 1990] has been analyzed with the proposed model. Figure 7 describes the tested column and the experimental mockup. 


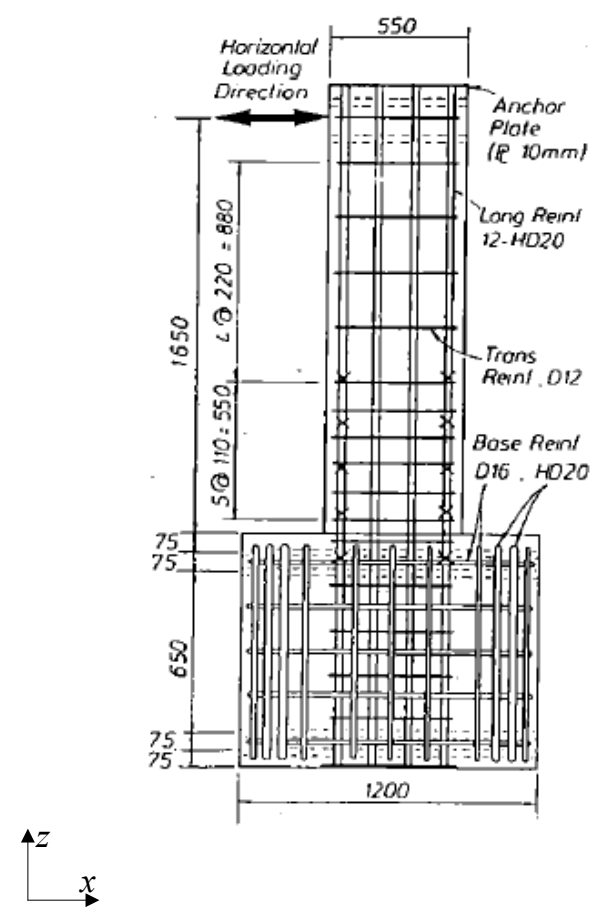

(b) Vertical section

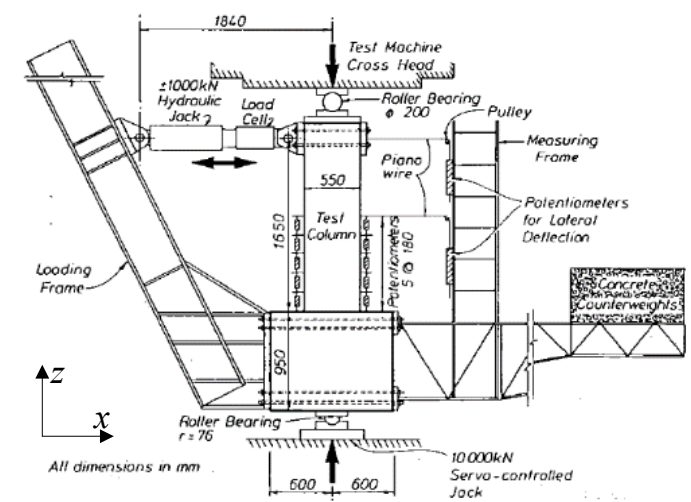

(a) Loading arrangements

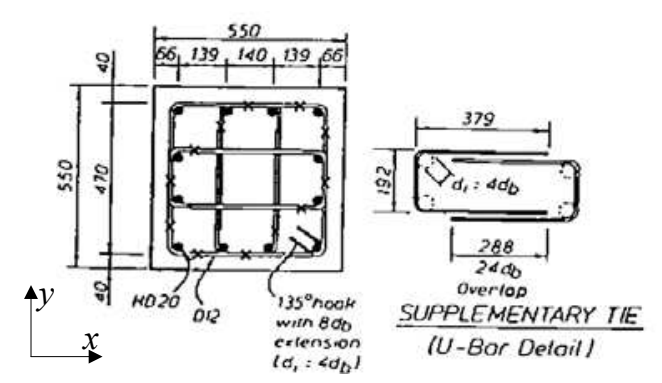

(c) Horizontal section

Figure 7. Experiment on the bridge RC column [Tanaka 1990]

Figure 7.b and Figure 7.c display the geometry of the column, dimensions are in mm. The column was loaded with constant force $0.1 f^{\prime} \mathrm{c} / \mathrm{A}_{\mathrm{g}}$ and a cyclic lateral displacement protocol was imposed by hydraulic jacks as shown in Figure 7.a. Concrete mechanical parameters were determined from standard cylinder tests. The characteristic value of compressive strength is $32 \mathrm{MPa}$ and the average value of secant deformation modulus is $27.65 \mathrm{GPa}$; Poisson ratio and shear deformation modulus were estimated as 0.2 and $11.52 \mathrm{GPa}$, respectively. Steel parameters were obtained from coupon tests. Table 1 displays the most relevant information regarding reinforcement steel. In Table 1, bars HD20 and D12 correspond to longitudinal and transverse reinforcement, respectively. $f_{\mathrm{u}}$ is the steel ultimate stress, $E_{\mathrm{s}}$ is the modulus of elasticity, $\varepsilon_{\mathrm{sh}}$ is the strain corresponding to the hardening onset, and $\varepsilon_{\mathrm{u}}$ is the ultimate strain.

Table 1. Reinforcement steel parameters for the bridge column

\begin{tabular}{ccccccc}
\hline Bar Id. & $\boldsymbol{D}_{\mathbf{b}}(\mathbf{m m})$ & $\boldsymbol{f}_{\mathbf{y}}(\mathbf{M P a})$ & $\boldsymbol{f}_{\mathbf{u}}(\mathbf{M P a})$ & $\boldsymbol{E}_{\mathbf{s}}(\mathbf{G P a})$ & $\boldsymbol{\varepsilon}_{\mathrm{sh}}$ & $\boldsymbol{\varepsilon}_{\mathrm{u}}$ \\
\hline $\mathrm{HD} 20$ & 20 & 511 & 675 & 200 & 0.0165 & 0.14 \\
\hline $\mathrm{D} 12$ & 12 & 325 & 429 & 200 & 0.015 & 0.14 \\
\hline
\end{tabular}

Figure 8 displays the imposed displacement law. 


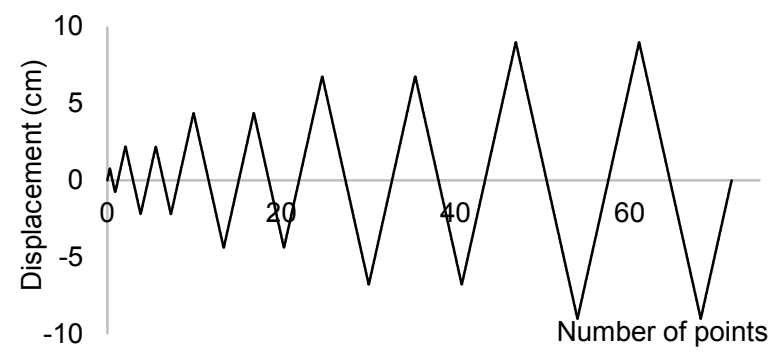

Figure 8. Imposed displacement law for the bridge column experiment

The results of the experiment showed stable hysteretic behavior, good energy dissipation and limited strength reduction up to the final stage. Substantial crushing of compressed cover concrete (spalling) was first observed near peak load during the first cycle. During the final stage, the visible damage was concrete crushing and slight buckling of longitudinal reinforcement bars.

The bond-slip model [Murcia-Delso, Shing 2015a] has been used in the simulation using the analyzed with the proposed model described in section 5. Figure 9 depicts the element discretization. Figure 9.a describes the concrete discretization with 3-D 8-node hexahedron solid elements (C3-D8R). Figure 9.b and Figure 9.c represent the steel and interface elements; steel is discretized with 2-node truss elements (T3-D2). Bond-slip effect is considered for the column longitudinal bars at the base of the column and development region in the footing, as shown in Figure 9.b; full bond conditions are assumed for the other segments of longitudinal bars as well as for transverse reinforcement because minimal bar slip is expected for these bars.

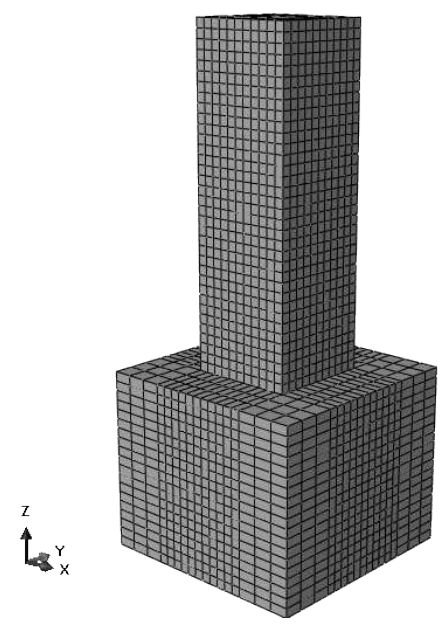

(a) Column discretization

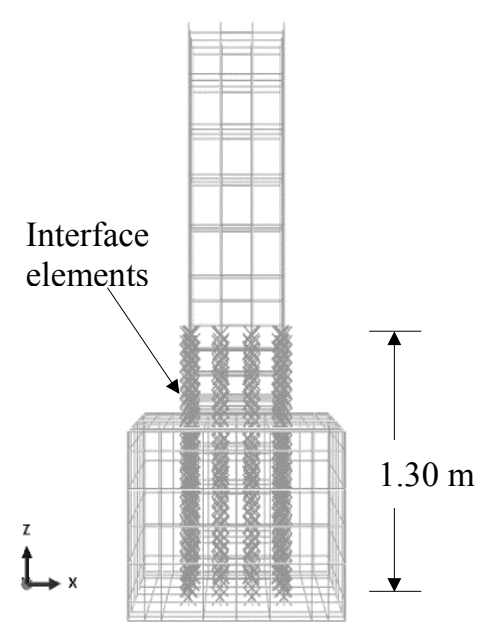

(b) Steel and interface elements

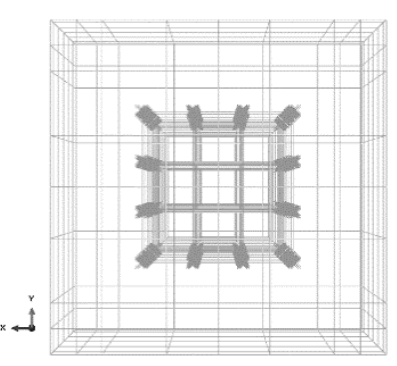

(c) Plan view of steel and interface elements

Figure 9. Finite element discretization of the bridge column

Steel behavior is described with a classical plastic model; isotropic hardening is used for stirrups, and nonlinear isotropic/kinematic hardening for longitudinal bars. Concrete behavior is simulated by implementing the methodology described in section 3 [Alfarah et al. 2017] in Abaqus code [Abaqus 2013] using the particular algorithm described in [Alfarah et al. 2017].

Figure 10.a displays plots of ratio $\varepsilon_{\mathrm{c}}^{\mathrm{pl}} / \varepsilon_{\mathrm{c}}^{\mathrm{ch}}$ vs. $\varepsilon_{\mathrm{c}}^{\mathrm{ch}}$, where $\varepsilon_{\mathrm{c}}^{\mathrm{pl}}$ refers to plastic compressive strain. Figure 10.b displays analogous plots for the tensile behavior $\left(\varepsilon_{\mathrm{t}}^{\mathrm{pl}} / \varepsilon_{\mathrm{t}}^{\mathrm{ck}}\right.$ vs. $\left.\varepsilon_{\mathrm{t}}^{\mathrm{ck}}\right)$. 


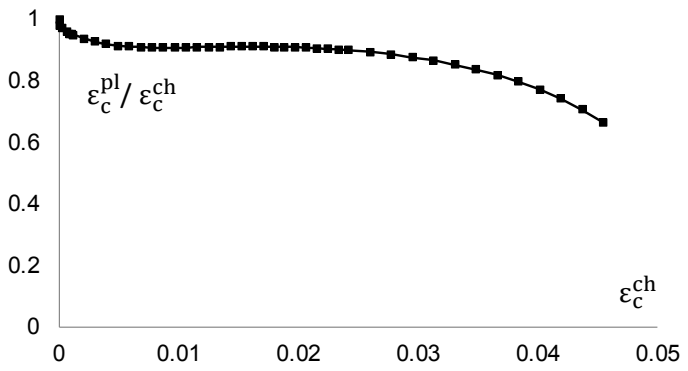

(a) Compression

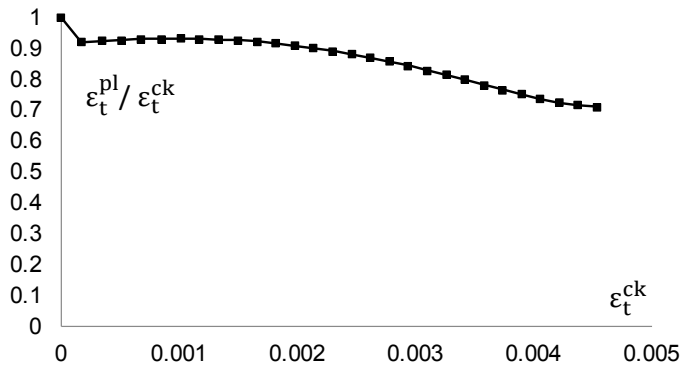

(b) Tension

Figure 10. Variation of ratios between plastic and crushing / cracking strains for the bridge column experiment

Figure 10 highlights that, in the proposed methodology, damage and plastic energy absorptions are not related, since ratios $\varepsilon_{\mathrm{c}}^{\mathrm{pl}} / \varepsilon_{\mathrm{c}}^{\mathrm{ch}}$ and $\varepsilon_{\mathrm{t}}^{\mathrm{pl}} / \varepsilon_{\mathrm{t}}^{\mathrm{ck}}$ do not approach zero when damage variables $d_{\mathrm{c}}$ and $d_{\mathrm{t}}$ are close to 1 [Alfarah et al. 2017]. Figure 10.a points out that the average of $\varepsilon_{\mathrm{c}}^{\mathrm{pl}} / \varepsilon_{\mathrm{c}}^{\mathrm{ch}}$ is approximately equal to 0.88 ; this magnitude is termed $b$ and is a required parameter in the implementation of the algorithm [Alfarah et al. 2017]. Table 2 displays the considered values of the parameters.

Table 2. Parameters for simulation of the first experiment

\begin{tabular}{ccccccccccc}
\hline $\begin{array}{c}\boldsymbol{f}_{\text {ck }} \\
(\mathbf{M P a})\end{array}$ & $\begin{array}{c}\boldsymbol{f}_{\text {cm }} \\
(\mathbf{M P a})\end{array}$ & $\begin{array}{c}\boldsymbol{f}_{\text {tm }} \\
(\mathbf{M P a})\end{array}$ & $\begin{array}{c}\boldsymbol{G}_{\text {ch }} \\
(\mathbf{N} / \mathbf{m m})\end{array}$ & $\begin{array}{c}\boldsymbol{G}_{\mathbf{F}} \\
(\mathbf{N} / \mathbf{m m})\end{array}$ & $\boldsymbol{b}$ & $\boldsymbol{a}_{\mathbf{c}}$ & $\boldsymbol{a}_{\mathbf{t}}$ & $\begin{array}{c}\boldsymbol{l}_{\text {eq }} \\
(\mathbf{m m})\end{array}$ & $\boldsymbol{b}_{\mathbf{c}}$ & $\boldsymbol{b}_{\mathbf{t}}$ \\
\hline 24 & 32 & 2.51 & 22.14 & 0.136 & 0.889 & 7.873 & 1 & 50 & 142.65 & 1381.74 \\
\hline
\end{tabular}

Figure 11 displays comparisons between experimental and numerical hysteresis loops calculated with the proposed model. In Figure 11.a, the numerical results are obtained by using $h_{\mathrm{c}}=0.9$ in all the body, and generating a discrete crack at the footing-column interface; normal friction contact condition is assumed at that interface. In Figure 11.b, the approach to represent concrete discontinuity described in subsection 5.3 is applied by assigning $h_{\mathrm{c}}=0.01$ to the first row of elements above the footing, $h_{\mathrm{c}}=0.1$ to the elements where bond-slip is considered (Figure 9.b), and $h_{\mathrm{c}}=0.9$ for the rest of the model (Figure 6). These values have been selected to provide the best fit with the experiment.

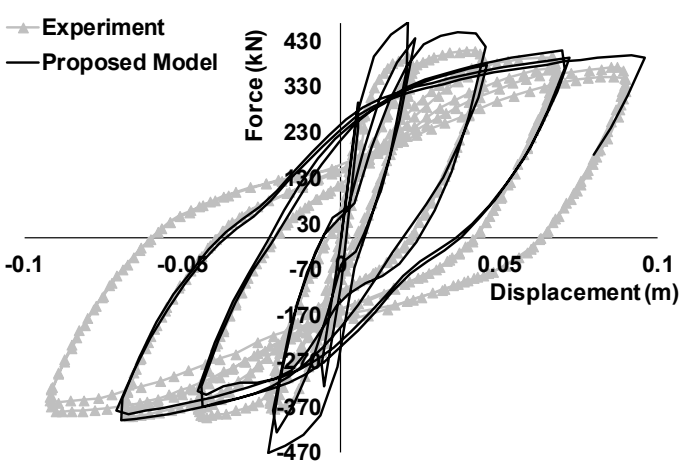

(a) Experiment and proposed formulation with a discrete crack

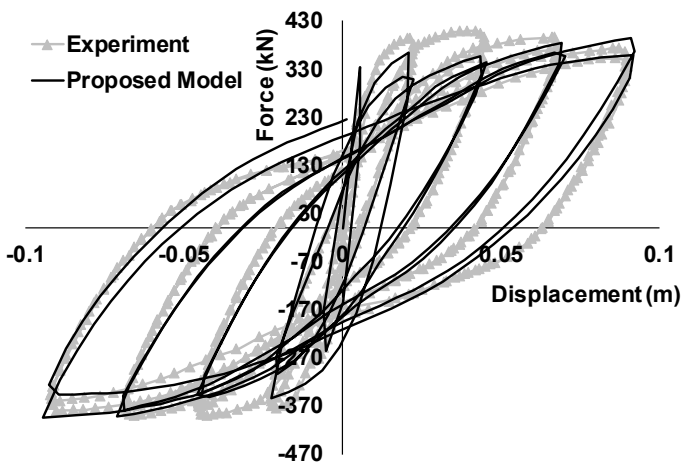

(b) Experiment and proposed formulation with reduced $h_{\mathrm{c}}$ (subsection 5.3)

Figure 11. Experimental and numerical force-displacement response of the bridge column test

Figure 11 shows that the proposed model provides a satisfactory agreement with test results, capturing initial stiffness, strength and stiffness degradation, and pinching. Plots from Figure 11.a show that the model with discrete crack is able to reproduce the main aspects of cyclic behavior; the analysis ended prematurely due to the large nonlinearity and the important separation between both blocks. The model with reduced $h_{\mathrm{c}}$ (Figure 11.b) captured suitably the dissipated energy from the experiment with difference $-1.66 \%$; conversely, the model with discrete crack (Figure 11.a) overestimated that energy by $22.88 \%$.

Figure 12 displays comparisons between pairs of plots obtained by numerical simulation with the proposed 
model and with a similar model assuming perfect bond between the reinforcement and the surrounding concrete. In Figure 12.a a discrete crack is introduced in the proposed model (as in Figure 11.a), and in Figure 12.b reduced values of $h_{\mathrm{c}}$ are considered (as in Figure 11.b).

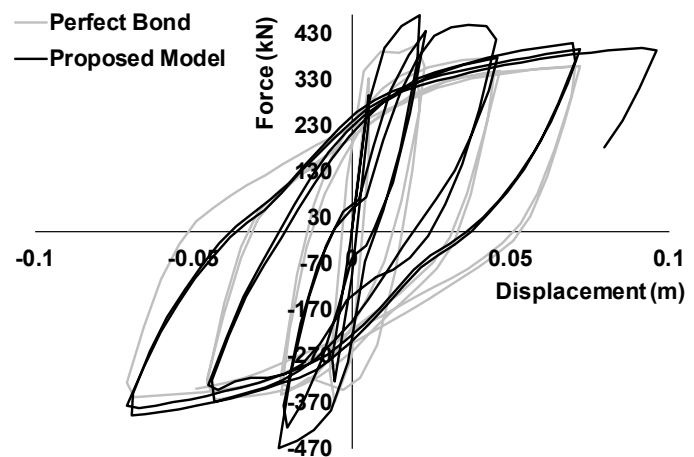

(a) Proposed formulation with a discrete crack vs. perfect bond

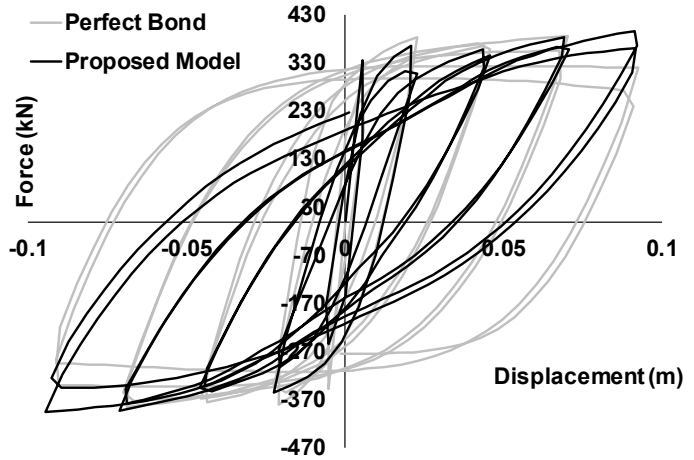

(b) Proposed formulation with reduced $h_{\mathrm{c}}$ (subsection 5.3) vs. perfect bond

Figure 12. Numerical force-displacement response of the bridge column test

Figure 12 highlights the relevance of bond-slip. Comparison between Figure 12.a and Figure 12.b shows that differences are more significant in the smeared model.

Comparison between Figure 11 and Figure 12 shows that the models with perfect bond reproduce satisfactorily the envelope behavior but lack to capture the unloading and reloading branches. The discrete crack model response in Figure 12.a exhibits some pinching due to the added flexibility at the column bottom; conversely, the smeared model response in Figure 12.b shows higher energy dissipation.

Experimental observations revealed buckling in the longitudinal reinforcement bars at column bottom [Tanaka 1990]. Figure 13 presents numerical (Figure 13.a and Figure 13.b) and experimental (Figure 13.c) representations of this failure. Figure 13.a displays the buckling that is detected at the last cycle, Figure 13.b shows the final damage state and Figure 13.c depicts the observed damage. Comparison between numerical and experimental results highlights the accuracy of the proposed formulation.

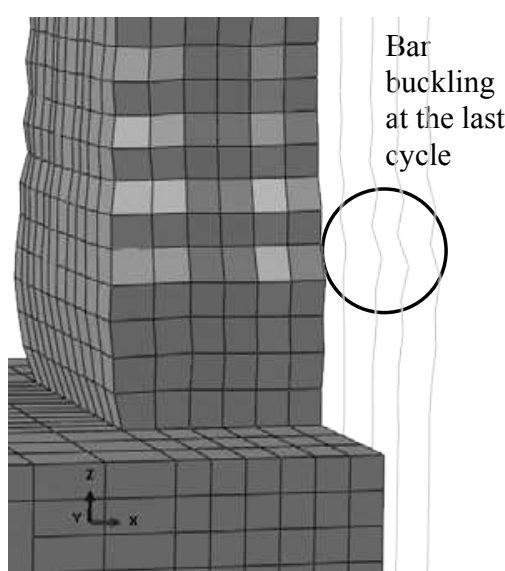

(a) Buckling in the longitudinal bars

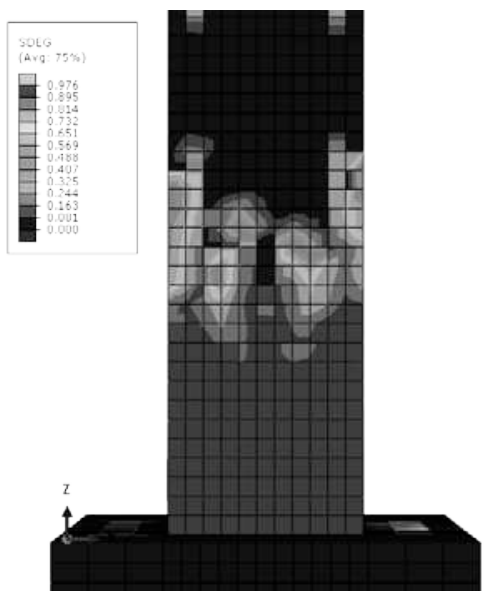

(b) Final damage state

Figure 13. Final state of the bridge column

\subsection{Building Frame}

This experiment [Pires 1990] consists in imposing a quasi-static cyclic displacement law to a laboratory 
single-bay, single-story 2-D RC frame. Figure 14.b describes the tested frame, and Figure 14.a and Figure 14.c display beam and columns sections, respectively. Figure 14.b shows that both columns were loaded with constant forces and that displacement was imposed to the top left joint. Noticeably, given the absence of distributed loads on beam, there was no initial cracking.

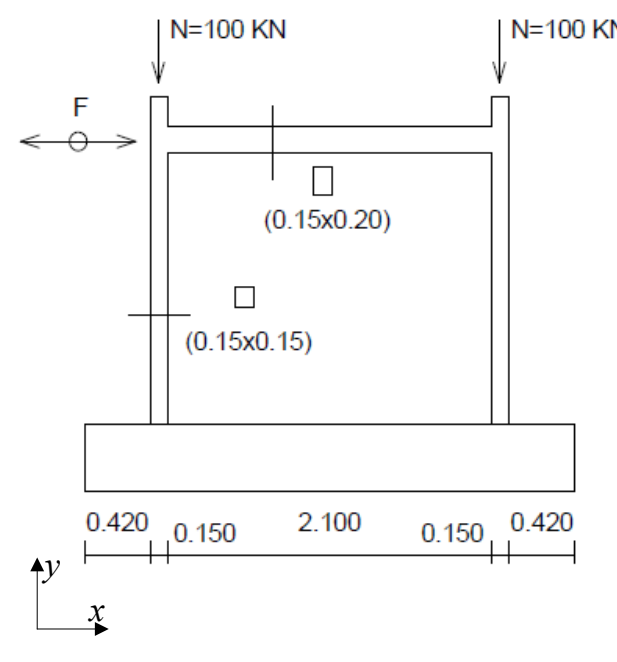

(b) Tested frame

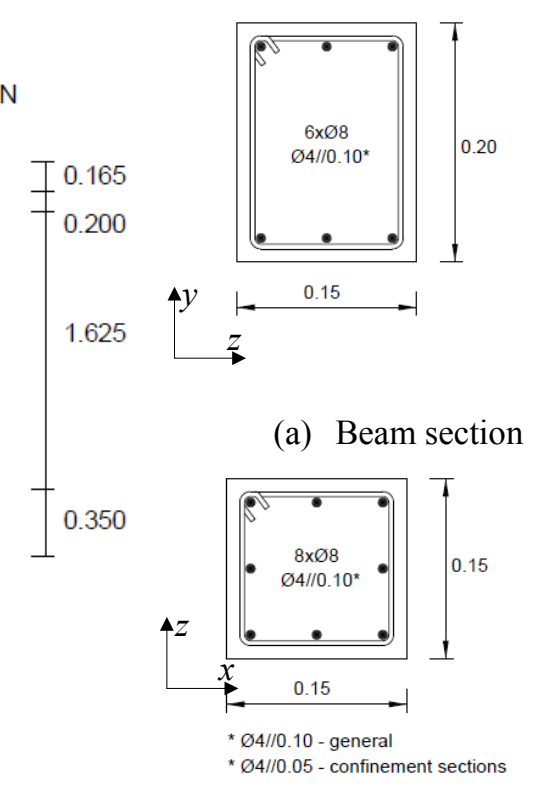

(c) Column section

Figure 14. RC frame experiment [Braz-César et al. 2008a, 2008b]

Mechanical parameters of materials are based on nominal values. The characteristic value of the concrete compressive strength is $20 \mathrm{MPa}$ (C20/25, [EN 1992 2004]), and the steel yield point is $400 \mathrm{MPa}$ for the longitudinal reinforcement and $500 \mathrm{MPa}$ for the stirrups [EN 10080 2006]. As described in Figure 14.c, in the critical end segments ("confinement sections"), closer stirrup spacing was used; the lengths of these segments are $40 \mathrm{~cm}$ in beam and $30 \mathrm{~cm}$ in columns.

Figure 15 displays the imposed displacement law.

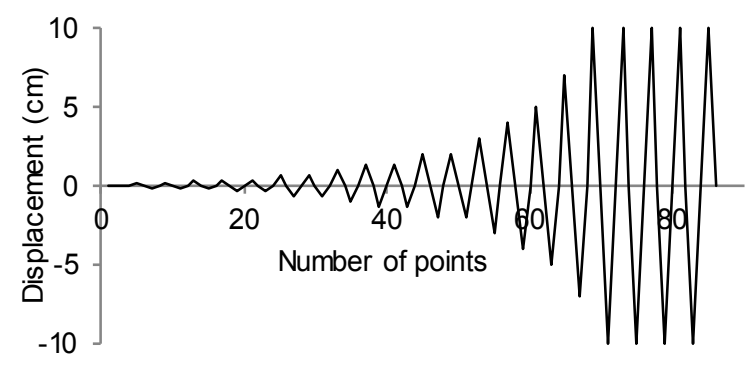

Figure 15. Imposed displacement law for the frame experiment

This frame had been previously simulated by [Braz-César et al. 2008a, 2008b] by using concentrated and distributed plasticity models.

Analogously to bridge column experiment [Tanaka 1990], this test is simulated by implementing the damage variables algorithm and the bond-slip model [Murcia-Delso, Shing 2015a] in Abaqus code [Abaqus 2013] using the modeling scheme described in section 5.

Table 3 displays the calculated values for the parameters of the damage variables methodology. 
Table 3. Parameters for simulation of the frame experiment

\begin{tabular}{ccccccccccc}
\hline $\begin{array}{c}f_{\text {ck }} \\
(\mathrm{MPa})\end{array}$ & $\begin{array}{c}f_{\mathrm{cm}} \\
(\mathrm{MPa})\end{array}$ & $\begin{array}{c}f_{\mathrm{tm}} \\
(\mathrm{MPa})\end{array}$ & $\begin{array}{c}G_{\mathrm{ch}} \\
(\mathrm{N} / \mathrm{mm})\end{array}$ & $\begin{array}{c}G_{\mathrm{F}} \\
(\mathrm{N} / \mathrm{mm})\end{array}$ & $b$ & $a_{\mathrm{c}}$ & $a_{\mathrm{t}}$ & $\begin{array}{c}l_{\mathrm{eq}} \\
(\mathrm{mm})\end{array}$ & $b_{\mathrm{c}}$ & $b_{\mathrm{t}}$ \\
\hline 20 & 28 & 2.222 & 21.12 & 0.133 & 0.97 & 7.873 & 1 & 21.6 & 56.57 & 541.45 \\
\hline 20 & 28 & 2.222 & 21.12 & 0.133 & 0.94 & 7.873 & 1 & 37 & 96.91 & 927.48 \\
\hline
\end{tabular}

This experiment is simulated using bond-slip elements where bars are expected to slip. Figure 16 displays the frame discretization; Figure 16.a shows the overall discretization, Figure 16.b presents a general view of steel and interface elements and Figure 16.c depicts a more detailed view of the right beam-column joint. As shown in Figure 16.b, bond-slip elements are assigned to the longitudinal bars along the column foundation, inside beam-column joints, at the column top and bottom ends, and at beam-ends. Noticeably, the proposed modeling scheme (section 5) allows that bar elements intersect in the same solid element without need to generate perpendicular holes nor to use double nodes. Regarding the approach described in subsection 5.3, similarly to Figure 6, $h_{\mathrm{c}}=0.01$ for the bottom and top row of elements inside the columns; then, $h_{\mathrm{c}}=0.1$ for the elements where bond-slip is considered (Figure 16), and $h_{\mathrm{c}}=0.9$ for the rest of the model. The results from this approach are compared with those after introducing discrete cracks right above the footings.

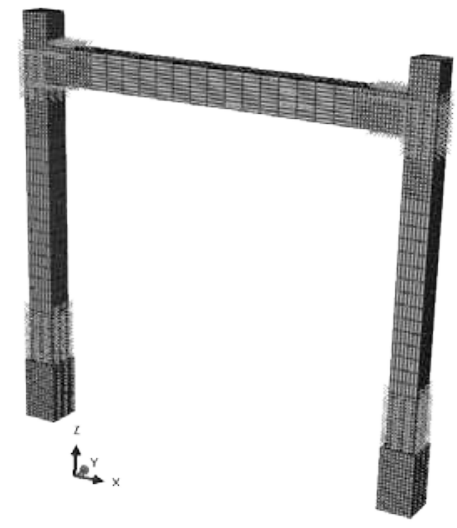

a) Frame discretization

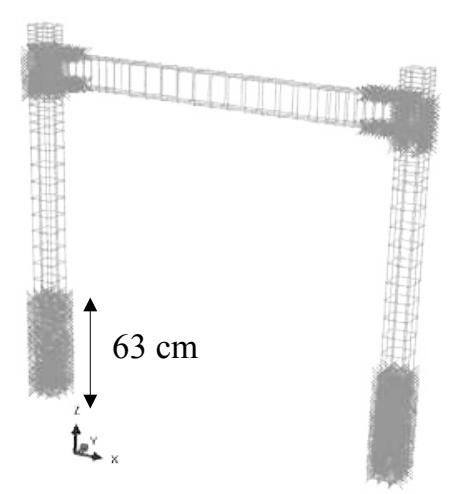

b) Steel and interface elements

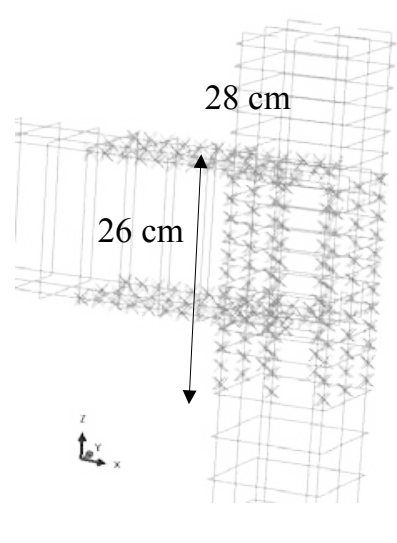

c) Interface elements at the right beam-column joint

Figure 16. Finite element discretization of the frame experiment

Analogously to Figure 11, Figure 17 displays comparisons between experimental and numerical hysteresis loops obtained with the proposed model. Plots from Figure 17 provide similar conclusions than Figure 11.

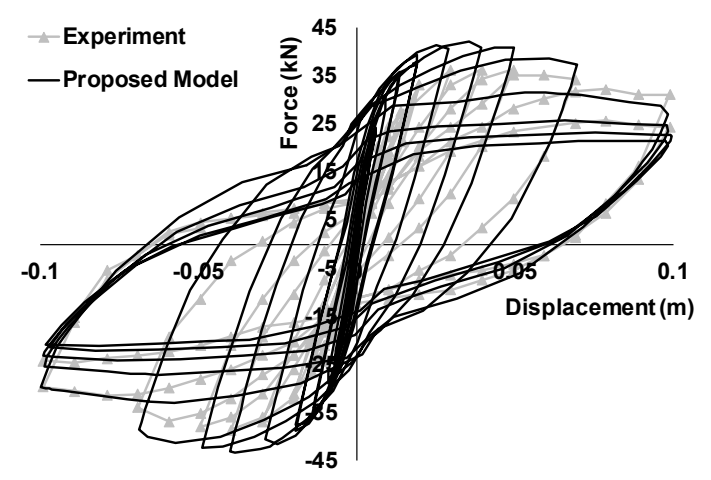

(a) Experiment and proposed formulation with a discrete crack

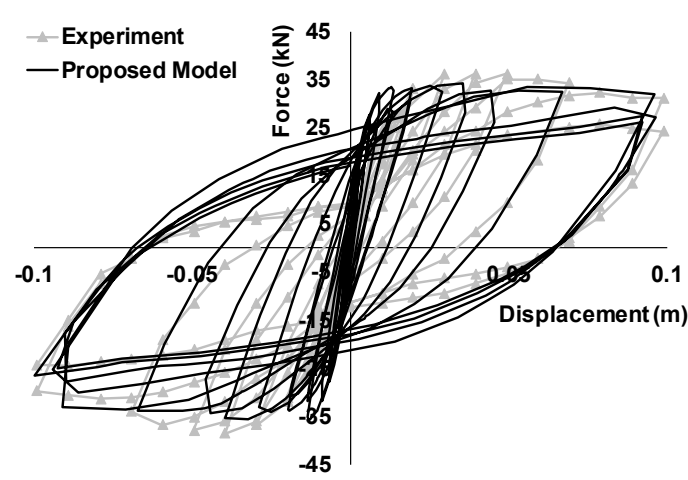

(b) Experiment and proposed formulation with reduced $h_{\mathrm{c}}$ (subsection 5.3)

Figure 17. Experimental and numerical force-displacement response of the frame test

Similarly to Figure 12, Figure 18 displays comparisons between numerical hysteresis loops obtained with the proposed model and assuming perfect bond. Figure 18 allows deriving parallel observations than Figure 
12.

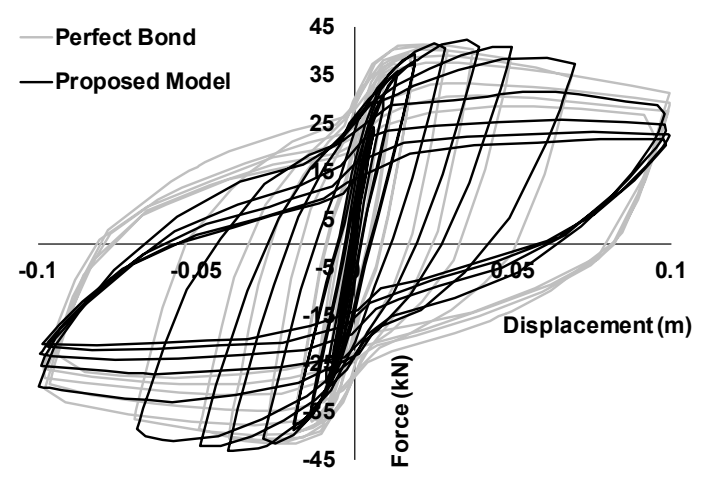

(a) Proposed formulation with a discrete crack vs. perfect bond

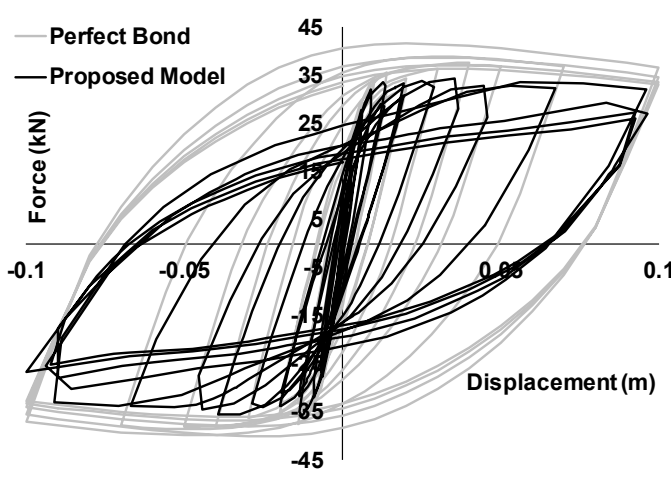

(b) Proposed formulation with reduced $h_{\mathrm{c}}$ (subsection 5.3) vs. perfect bond

Figure 18. Numerical force-displacement response of the frame experiment

\section{Conclusions}

An integrated continuum FEM model is proposed for monotonic and cyclic simulation of RC frames. The model combines the methodology proposed by some of the authors for calculating the damage variables of CPDM and the 3-D interface bond-slip model developed by one of the authors. A new technique to integrate the interface model in a continuum FEM model of regions with crossing bars is presented in this paper. The proposed model is used to simulate two experiments consisting in imposing cyclic displacement laws to an RC column and a frame. These experiments are also simulated with the same model although assuming perfect bond conditions.

Obtained results show that the proposed model is able to predict the actual behavior of highly damaged RC elements and frames, capturing strength reduction, stiffness degradation and pinching. This model uses only a reduced number of parameters, and the authors believe that no calibration with experimental results is required; more research is currently in progress to further validate this statement. Comparison with the results obtained assuming perfect bond points out the high relevance of bond-slip in the hysteretic behavior and the energy dissipation capacity.

The proposed integrated model can constitute a practical tool for accurate simulation of highly damaged medium-size RC structures, both in research and in conventional analyses. It can be also used to calibrate more simplified models.

\section{Acknowledgements}

This work has received financial support from Spanish Government under projects BIA2014-60093-R, MAT2014-60647-R and CGL2015-6591 and from European Commission under projects ERC-2012-AdG-320815 and PIRSES-GA-2013-612607. These supports are gratefully acknowledged.

\section{References}

[1] Abaqus analysis user's manual version 6.11.3. (2013). Pawtucket (RI): Hibbitt, Karlsson \& Sorensen.

[2] Alfarah B (2017). Advanced Computationally Efficient Modelling of RC Structures Nonlinear Cyclic Behavior. Doctoral dissertation, Technical University of Catalonia.

[3] Alfarah B, López-Almansa F, Oller S (2017). New methodology for calculating damage variables evolution in Plastic Damage Model for RC structures. Engineering Structures (published on-line).

[4] Ali A, Kim D, Cho SG (2013). Modeling of Nonlinear Cyclic Load Behaviour of I-shaped Composite Steel-Concrete Shear Walls of Nuclear Power Plants, Nuclear Engineering and Technology 45(1).

[5] Al-Rub A, Kim S-M (2010). Computational applications of a coupled plasticity-damage constitutive 
model for simulating plain concrete fracture, Engineering Fracture Mechanics. 77:1577-1603. doi:10.1016/j.engfracmech.2010.04.007.

[6] Belytschko T, Fish J, Engelmann BE. (1988). A finite element with embedded localization zones. Computer Methods in Applied Mechanics and Engineering 70:59-89.

[7] Birtel V, Mark P (2006). Parametrised Finite Element Modelling of RC Beam Shear Failure. Abaqus Users Conference 95-108.

[8] Braz-César MT, Oliveira D, Barros RC (2008a). Comparison of cyclic response of reinforced concrete infilled frames with experimental results, $14^{\text {th }}$ World Conference on Earthquake Engineering (14WCEE), Beijing, China.

[9] Braz-César MT, Oliveira D, Barros RC (2008b). Numerical validation of the experimental cyclic response of reinforced concrete frames. In "Trends in Computational Structures Technology" Topping BHV, Papadrakakis M Eds., Saxe-Coburg.

[10] Burlion N, Gatuingt F, Pijaudier-Cabot G, Daudeville L. (2000). Compaction and tensile damage in concrete: constitutive modelling and application to dynamics, Comput. Methods Appl. Mech. Engrg. 183:291-308

[11] Car E, Zalamea F, Oller S, Miquel J, Oñate E. (2002). Numerical simulation of fiber reinforced composite materials. Two procedures. International Journal of Solids and Structures. 39(7):1967-1986.

[12] Carol I, Rizzi E, Willam KJ. (2001). On the formulation of anisotropic elastics degradation. II. Generalized pseudo-Rankine model for tensile damage. International Journal of Solids and Structures 38:519-546.

[13] CEB-FIP (2010). Model Code 2010. Thomas Telford, London.

[14] Chen AC, Chen WF. (1975). Constitutive relations for concrete. Journal of Engineering Mechanics Division, ASCE 101:465-481.

[15] Cox JV, Herrmann LR. (1998). Development of a plasticity bond model for steel reinforcement, Mechanics of Cohesive-Frictional Materials, 3(2):155-180.

[16] Daoud A, Maurel O, Laborderie C. (2012). Mesoscopic modeling of the interaction between steel reinforcement and the early-age cracking during cement hydration, Bond in Concrete, Brescia, Italy.

[17] Deaton JB. (2013). Nonlinear finite element analysis of reinforced concrete exterior beam-column joints with nonseismic detailing. PhD Thesis, School of Civil and Environmental Engineering, Georgia Institute of Technology.

[18] Eligehausen R, Popov EP, Bertero VV. (1983). Local bond stress — slip relationships of deformed bars under generalized excitations. UCB/EERC-83/23, Earthquake Engineering Research Center, Univ. of California, Berkeley.

[19] EN 10080 (2006). Steel for the reinforcement of concrete, weldable, ribbed reinforcing steel. European Committee for Standardization.

[20] EN 1992 (2004). Eurocode 2: Design of concrete structures. European Committee for Standardization.

[21] Faria R, Oliver J, Cervera M. (1998). A strain-based plastic viscous-damage model for massive concrete structures, Int. J. Solids Structures 35(14), 1533-1558

[22] Gan, Y (2000). Bond stress and slip modeling in nonlinear finite element analysis of reinforced concrete structures. M.A.Sc. Thesis, Department of Civil Engineering, University of Toronto.

[23] Grassl P, Jirásek M. (2006). Damage-plastic model for concrete failure. International Journal of Solids and Structures, 43(22-23):7166-7196. (doi:10.1016/j.ijsolstr.2006.06.032).

[24] Häussler-Combe U, Hartig J (2008). Formulation and numerical implementation of a constitutive law for concrete with strain-based damage and plasticity. International Journal of Non-Linear Mechanics 43:399-415. doi:10.1016/j.ijnonlinmec.2008.01.005.

[25] Jirásek M, Zimmermann T (2001). Embedded crack model: I. Basic formulation. Int. J. Numer. Meth. Engng 50:1269-1290.

[26] Krätzig WB, Pölling R (2004). An elasto-plastic damage model for reinforced concrete with minimum number of material parameters, Computer and Structures 82(15-16): 1201-1215.

[27] Lee J, Fenves GL (1998). Plastic-Damage Model for Cyclic Loading of Concrete Structures, Engineering Mechanics 124(8):892-900.

[28] Lemaitre J. (1992). A course on damage mechanics, Springer Verlag. 
[29] Liang X, Sritharan S. (2014). An Investigation of Bond-Slip Behaviour of Reinforcing Steel Subjected to Inelastic Strains. Tenth U.S. National Conference on Earthquake Engineering Frontiers of Earthquake Engineering.

[30] Lin FB, Bazant ZP, Chern JC, Marchertas AH. (1987). Concrete model with normality and sequential identification. Computers and Structures 26:1011-1025.

[31] López-Almansa F, Alfarah B, Oller S (2014). Numerical simulation of RC frame testing with Damage Plasticity Model. Comparison with Simplified Models, $15^{\text {th }}$ European Conference on Earthquake Engineering (15ECEE), Istanbul, Turkey.

[32] Lowes LN, Moehle JP, Govindjee S. (2004). Concrete-Steel Bond Model for Use in Finite Element Modeling of Reinforced Concrete Structures, ACI Structural Journal, Vol. 101, No. 4, July-August, 501-511.

[33] Lubliner J, Oliver J, Oller S, Oñate E (1989). A plastic-damage model for concrete, Solids and Structures, 25(3):299-326.

[34] Luccioni B, Oller S, Danesi R. (1996). Coupled plastic-damaged model, Comput. Methods Appl. Mech. Engrg 129:81-89.

[35] Maekawa, K., Pimanmas, A., Okamura, H., Nonlinear mechanics of reinforced concrete, Ed. Spon Press, New York, NY, 2003.

[36] Malvar, L.J. (1992): Bond reinforcement under controlled confinement. ACI Materials Journal 89(6), 711-721.

[37] Mazars J. (1984). Application de la mécanique de l'endommagement au comportement non linéaire et à la rupture du béton de structure. Doctoral Thesis, University of Paris.

[38] Mazars J, Pijaudier-Cabot G. (1989). Continuum damage theory-application to concrete. Journal of Engineering Mechanics ASCE, 115(2):345-365.

[39] Monti G, Filippou FC, Spacone E. (1997) Finite element for anchored bars under cyclic load reversals, ASCE Journal of Structural Engineering, 123(5):614-623.

[40] Monti G, Spacone E. (2000). Reinforced concrete fiber beam element with bond-slip, Journal of Structural Engineering, 126(6):654-661.

[41] Murcia-Delso J. (2013). Bond-slip behavior and development of bridge column longitudinal reinforcing bars in enlarged pile shafts. PhD Thesis, Dept. of Structural Engineering, Univ. of California, San Diego.

[42] Murcia-Delso J, Stavridis A, Shing PB. (2013). Bond strength and cyclic bond deterioration of large-diameter bars. ACI Struct. J., 110(4):659-669.

[43] Murcia-Delso J, Shing PB. (2015a). Bond-Slip Model for Detailed Finite-Element Analysis of Reinforced Concrete Structures. J. Struct. Eng., ASCE, 0733-9445/04014125(10).

[44] Murcia-Delso J, Shing PB. (2015b). Elastoplastic Dilatant Interface Model for Cyclic Bond-Slip Behavior of Reinforcing Bars. J. Eng. Mechanics, ASCE, 10.1061/(ASCE)EM.1943-7889.0000994.

[45] Nguyen GD, Houlsby GT. (2004). A thermodynamic approach to constitutive modelling of concrete, Proceedings of the $12^{\text {th }}$ conference, Association for Computational Mechanics in Engineering (ACME-UK), Cardiff UK.

[46] Nguyen GD, Korsunsky A. (2008). Development of an approach to constitutive modelling of concrete: damage coupled with plasticity. International Journal of Solids and Structures, 45(20):5483-5501.

[47] Oliver J. (1989). A consistent characteristic length for smeared cracking models. Int J Numer Methods Engng; 28:461-74.

[48] Oller S (1988). A continuous damage model for frictional materials (in Spanish), Doctoral Dissertation, Technical University of Catalonia.

[49] Oller S, Car E, Oñate E. (2000). A numerical approach to simulate the behavior of fiber reinforced composite materials. European Congress on Computational Methods in Applied Engineering, ECCOMAS-2000. Barcelona.

[50] Oller S. (2014). Numerical Simulation of Mechanical Behavior of Composite Materials. CIMNE-Springer, Barcelona, Spain.

[51] Ožbolt J, Lettow S, Kožar I. (2002). Discrete Bond Element for 3-D Finite Element Analysis of Reinforced Concrete Structures. Proceedings of the $3^{\text {rd }}$ International Symposium: Bond in Concrete from research to standards. Budapest: University of Technology and Economics. 
[52] PEER. (2015). Open System for Earthquake Engineering Simulation (OpenSEES). Pacific Earthquake Engineering Research Center, Berkeley.

[53] Pires F (1990). Influência das paredes de alvenaria no comportamento de estruturas reticuladas de betão armado sujeitas a acções horizontais, PhD Thesis, LNEC, Lisbon, Portugal (in Portuguese).

[54] Rabczuk T, Akkermann J, Eibl J. (2005). A numerical model for reinforced concrete structures, International Journal of Solids and Structures, 42(5-6):1327-1354.

[55] Salari MR, Saeb S, Willam KJ, Patchet SJ, Carrasco RC. (2004). A coupled elastoplastic damage model for geomaterials, Comput. Methods Appl. Mech. Engrg. 193(27-29):2625-2643.

[56] Shima H, Chou L, Okamura H. (1987). Bond characteristics in post-yield range of deformed bars. Proc. JSCE, 6(387):113-124.

[57] Simo JC, Oliver J. (1994). A new approach to the analysis and simulation of strain softening in solids. In Fracture and Damage in Quasibrittle Structures, E\&FN:25-39.

[58] Sinha BP, Gerstle KH, Tulin LG (1964). Stress-strain relations for concrete under cyclic loading, ACI Structural Journal 62(2):195-210.

[59] Spacone E, Filippou FC, Taucer FF. (1996). Fiber beam-column model for nonlinear analysis of R/C frames. Part I: Formulation, Earthquake Engineering and Structural Dynamics, 25(7):711-725.

[60] Tanaka H. (1990). Effect of Lateral Confining Reinforcement on the Ductile Behaviour of Reinforced Concrete Columns. Doctoral Dissertation. University of Canterbury, New Zealand.

[61] Vecchio F, Collins M. (1986). The modified compression-field theory for reinforced concrete elements subjected to shear, ACI Journal, 83:219-231.

[62] Voyiadjis GZ, Ziad N. Taqieddin, Kattan PI. (2008). Anisotropic damage-plasticity model for concrete. International Journal of Plasticity 24:1946-1965.

[63] Yu T, Teng JG, Won YL, Dong SL (2010). Finite element modeling of confined concrete-II: Plastic-damage model. Journal of Engineering Structures 32:680-691. doi:10.1016/j.engstruct.2009.11.013.

[64] Zhao J, Sritharan S. (2007). Modeling of strain penetration effects in fiber-based analysis of reinforced concrete structures. ACI Structural Journal, 104(2):133-141.

[65] Zheng FG, Wu ZR, Gu CS, Bao TF, Hu J (2012). A plastic damage model for concrete structure cracks with two damage variables. Science China, 55(11):2971-2980.

\section{List of symbols}

\section{Roman letters}

$a_{\mathrm{c}} / a_{\mathrm{t}} / b_{\mathrm{c}} / b_{\mathrm{t}}$ : dimensionless coefficients in equations (9), (10) and (11)

$b: \varepsilon_{\mathrm{c}}^{\mathrm{pl}} / \varepsilon_{\mathrm{c}}^{\mathrm{ch}}$ ratio (Table 2 and Table 3 )

$D_{\mathrm{b}}$ : reinforcement bar diameter

$d / d_{\mathrm{c}} / d_{\mathrm{t}}$ : damage variable / compression damage variable / tension damage variable

$E / E_{0}$ : modulus of deformation / undamaged modulus of deformation

$E_{s}$ : steel modulus of elasticity

$f / f_{\mathrm{cm}} / f_{\mathrm{tm}} / f_{\mathrm{c} 0} / f_{\mathrm{t} 0} / f_{\mathrm{ck}}$ : stress strength / concrete compressive stress strength / concrete tensile stress strength

/ limit stress of linear compressive branch / limit stress of linear tensile branch / characteristic value of concrete compressive strength

$f_{\mathrm{y}} / f_{\mathrm{u}}$ : steel yield point / ultimate stress

$G / G_{\mathrm{ch}} / G_{\mathrm{F}}$ : flow potential / crushing energy per unit area / fracture energy per unit area

$g_{\mathrm{c}} / g_{\mathrm{t}}$ : compressive / tensile energies per unit volume dissipated by damage along entire deterioration process

$h_{\mathrm{c}} / h_{\mathrm{t}}$ : weighting factors accounting for stiffness recovery

$l_{\text {eq }}$ : mesh size (finite element characteristic length)

$r^{*}$ : stress state; for uniaxial stress $r^{*}\left(\sigma_{11}\right)=1$ for tension and $r^{*}\left(\sigma_{11}\right)=0$ for compression

$S_{1} / S_{2} / S_{3}$ : relative normal displacement / longitudinal slip / transverse slip

$S_{\text {peak }} / S_{\max }^{+} / S_{\max }^{-} / S_{\text {cum }}$ : peak slip / maximum positive slip / maximum negative slip / cumulated slip

$S_{\mathrm{R}}$ : clear spacing between bar ribs

$s_{\mathrm{c}} / s_{\mathrm{t}}$ : coefficients accounting for stress state and stiffness recovery effects 


\section{Greek letters}

$\varepsilon_{\mathrm{s}} / \varepsilon_{\mathrm{y}} / \varepsilon_{\mathrm{sh}} / \varepsilon_{\mathrm{u}}:$ axial steel strain / yielding steel strain / hardening steel strain / ultimate steel strain $\varepsilon_{\mathrm{c}}^{\mathrm{ch}} / \varepsilon_{\mathrm{t}}^{\mathrm{ck}}$ : crushing compressive strain / cracking tensile strain

$\varepsilon_{\mathrm{c}}^{\mathrm{pl}} / \varepsilon_{\mathrm{t}}^{\mathrm{pl}}$ : plastic compressive / tensile strain

$\rho_{\mathrm{b}, \mathrm{s}} / \rho_{\mathrm{f}, \mathrm{s}}$ : reduction factor in bar bearing resistance accounting for steel yielding in tension / reduction factor in bar friction resistance accounting for steel yielding in tension

$\rho_{\mathrm{b}, \mathrm{c}} / \rho_{\mathrm{f}, \mathrm{c}}$ : reduction factor in bar bearing resistance accounting for slip history / reduction factor in bar friction resistance accounts for slip history

$\rho_{\mathrm{n}}$ : reduction factor accounting for opening of splitting cracks

$\sigma_{1}$ : normal bond stress

$\sigma / \sigma_{11}$ : normal stress / first principal uniaxial stress

$\tau_{2} / \tau_{\max } / \tau_{\mathrm{b}} / \tau_{\mathrm{f}}$ : longitudinal shear bond stress / peak bond strength / due to bar bearing resistance/ due to friction resistance

$\tau_{3}$ : transverse shear bond stress 